\title{
A Machine Learning-Based Model for Predicting Atmospheric Corrosion Rate of Carbon Steel
}

\author{
Ngoc-Long Tran, Trong-Ha Nguyen, Van-Tien Phan, and Duy-Duan Nguyen $\mathbb{C}$ \\ Department of Civil Engineering, Vinh University, Vinh 461010, Vietnam \\ Correspondence should be addressed to Duy-Duan Nguyen; duan468@gmail.com
}

Received 20 August 2021; Revised 8 November 2021; Accepted 24 November 2021; Published 14 December 2021

Academic Editor: Mikhail Zheludkevich

Copyright (c) 2021 Ngoc-Long Tran et al. This is an open access article distributed under the Creative Commons Attribution License, which permits unrestricted use, distribution, and reproduction in any medium, provided the original work is properly cited.

\begin{abstract}
The purpose of this study is to develop a practical artificial neural network (ANN) model for predicting the atmospheric corrosion rate of carbon steel. A set of 240 data samples, which are collected from the experimental results of atmospheric corrosion in tropical climate conditions, are utilized to develop the ANN model. Accordingly, seven meteorological and chemical factors of corrosion, namely, the average temperature, the average relative humidity, the total rainfall, the time of wetness, the hours of sunshine, the average chloride ion concentration, and the average sulfur dioxide deposition rate, are used as input variables for the ANN model. Meanwhile, the atmospheric corrosion rate of carbon steel is considered as the output variable. An optimal ANN model with a high coefficient of determination of 0.999 and a small root mean square error of $0.281 \mathrm{mg} / \mathrm{m}^{2}$.month is retained to predict the corrosion rate. Moreover, the sensitivity analysis shows that the rainfall and hours of sunshine are the most influential parameters on predicting the atmospheric corrosion rate, whereas the average chloride ion concentration, the average temperature, and the time of wetness are less sensitive to the atmospheric corrosion rate. An ANN-based formula, which accommodates all input parameters, is thereafter proposed to estimate the atmospheric corrosion rate of carbon steel. Finally, a graphical user interface is developed for calculating the atmospheric corrosion rate of carbon steel in tropical climate conditions.
\end{abstract}

\section{Introduction}

Atmospheric corrosion is considered as an electrochemical nonlinear and complex phenomenon, which is mostly depending on external factors and material properties. It is a challenge to evaluate the influence of these parameters on the degradation of materials, specifically, for structures exposed to various climatic conditions.

In fact, data of the atmospheric corrosion can be obtained properly based on realistic measurements. Nevertheless, there is still some problem related to the mechanism of the atmospheric corrosion and the effects of environmental parameters on this phenomenon. Among those, the potential interaction between the pollutants and the meteorological parameters is the one of critical issues. Closer looking into these problems would be very useful and provide a better understanding of the atmospheric corrosion process.
In the last few decades, atmospheric corrosion has been an interesting topic for researchers around the world. Kallias et al. [1] proposed a deterioration modeling and performed the assessment of metallic bridges affected by atmospheric corrosion. Several studies investigated the atmospheric corrosion process of metals considering multiple environmental factors [2-4]. It was demonstrated that the presence of atmospheric pollutants sulfur dioxide in urban and industrial atmospheres and chloride concentration in marine atmospheres affected the corrosion rate of metal significantly. The effects of relative humidity on the atmospheric corrosion were evaluated in some studies [5-9]; meanwhile, the influence of temperature on the atmospheric corrosion was demonstrated in the work of Kong et al. [10]. They showed that the corrosion rate of materials was increased as a function of temperature and relative humidity. A multiscale model for predicting atmospheric corrosion was proposed by Cole et al. [9], in which Australian conditions 
and marine aerosols were considered. Besides, the effects of rainfall on the atmospheric corrosion rate were investigated by several studies $[11,12]$. However, several studies pointed out that the chloride ions $\left(\mathrm{Cl}^{-}\right)$coming from the sea and sulfur dioxide $\left(\mathrm{SO}_{2}\right)$ are the most important atmospheric corrosive agents [13-16].

A prediction of the atmospheric corrosion accounting for exposing time, relative humidity, temperature, time of wetness, and pollutant concentration was proposed by Tidblad [17]. The quantitative relationships of environmental factors on the corrosion process were presented using the basic linear model $[18,19]$, the basic log-linear model [19-21], and dose-response functions [22-24]. Empirical equations to calculate the atmospheric corrosion rate were also proposed by some studies [19, 21, 25]. However, these equations only considered few input parameters, which are sulfur dioxide deposition rate, chloride, and time of wetness. Also, the atmospheric corrosion is controlled by various external factors of corrosion and pollution parameters such as humidity, temperature, and pollutants. Additionally, those atmospheric corrosion models are only valid for specific local geographical conditions. As the local geographical condition changed, such corrosion models are no longer applicable. Therefore, a sufficient model, which can cover various environmental factors, is still needed for predicting the atmospheric corrosion rate of carbon steel.

Artificial intelligence (AI) models have been commonly utilized in predicting corrosion behaviors of steel structures. Seghier et al. [26] estimated the maximum pitting corrosion depth in oil and gas pipelines using support vector regression (SVR) combined with optimization techniques such as Genetic Algorithm and particle swarm optimization and firefly algorithm (FFA). They demonstrated that the SVR-FFA model had superior performance compared with other considered models. In the study of Seghier et al. [27], the authors applied various data-driven models, which are artificial neural networks (ANNs), M5 tree, multivariate adaptive regression splines, locally weighted polynomials, kriging, and extreme learning machines, for calculating the maximum pitting corrosion depth of pipelines. Recently, a hybrid soft computing model, namely, multilayer perceptron-marine predators algorithm, was proposed for predicting the corrosion rate in the suspension bridge cables [28]. Diao et al. [29] developed corrosion rate models for low-alloy steels using the random forest and gradient boosting decision tree algorithms.

ANNs, an example of the most powerful algorithms of machine learning models, have been widely applied for metal sciences and atmospheric corrosion fields due to their advantages [30-34]. Those typical benefits are as follows: (1) ANN is a nonlinear model, which is easy to use and understand compared to statistical methods, and (2) ANNs allow the modeling of physical phenomena in complex systems without requiring explicit mathematical representations. Their findings showed that neural network models had a reliable prediction with a small error and a large coefficient of determination value $\left(R^{2}\right)$. The ANN models were effective for various investigations such as thickness prediction of sherardizing coating [31], corrosion of metals in equatorial climate [33], and corrosion of copper in Valparaiso (Chile) [34]. Particularly, ANN was used for predicting the penetration of corrosion or the corrosion rate of carbon steel considering input parameters such as humidity, temperature, time of wetness, precipitation, sulfur dioxide concentration $\left(\mathrm{SO}_{2}\right)$, and chloride deposition rate $\left(\mathrm{Cl}^{-}\right)[30,35]$. It was demonstrated that ANN models predicted the corrosion rate accurately with $R^{2}$ values of 0.90 in the work of Pintos et al. [35] and 0.998 in the work of Díaz and López [30]. It should be noted that the database used in the study of Pintos et al. [35] was measured from the IberoAmerica region. Besides, the effects of temperature and hours of sunshine were not considered in the study of Díaz and López [30]. Additionally, it was stated that ultraviolet light can activate the metal surface and then lead to a sooner initiation and a faster rate of corrosion process [36]. Therefore, the influence of sunshine hours, an important meteorological parameter, on the corrosion rate needs to be considered in the predicted model. Moreover, ANN-based explicit formulas or practical tools have not been proposed to apply the ANN model for realistic engineering problems so far.

The purpose of this study is to develop a practical ANN model, which can be readily applied for predicting the atmospheric corrosion rate $(K)$ of carbon steel. A total of 240 experimental data samples are used to establish the ANN model. Seven external factors, which are the average temperature $(\mathrm{T})$, average relative humidity $(\mathrm{RH})$, total rainfall (Rf), time of wetness (TOW), hours of sunshine (HoS), $\mathrm{Cl}^{-}$, and $\mathrm{SO}_{2}$ deposition rate, are considered as input variables of the ANN model. The performances of the ANN model are also compared with those of three existing empirical formulas and three regression models. Moreover, the influences of all input variables on the predicted corrosion rate are investigated thoroughly. Eventually, an ANN-based equation and a graphical user interface (GUI) tool are established to predict the atmospheric corrosion rate of carbon steel.

\section{Data Collection}

A set of 240 measured data samples of the atmospheric corrosion under tropical climate conditions in Vietnam were used to build up the ANN model. These databases were provided by the report of the Center for Material Failure Analysis [37], in which the data points were recorded in 2 years. Seven parameters, namely, T, RH, Rf, TOW, HoS, $\mathrm{Cl}^{-}$, and $\mathrm{SO}_{2}$, were involved as input parameters. It should be noted that the atmospheric corrosion rate was measured based on the weight loss of carbon steel samples. The relationship between corrosion rate $(K)$ and weight loss is expressed by the following equation [38]:

$$
K=\frac{m_{1}-m_{2}}{S \times t},
$$

where $m_{1}$ and $m_{2}$ are the weights of samples before and after corrosion, respectively; $S$ is the area of sample surface; $t$ is the corrosion time considered.

The summary of the statistical properties of the input parameters is presented in Table 1. It should be noted that 
TABLE 1: Statistic properties of the experimental data.

\begin{tabular}{|c|c|c|c|c|c|c|c|c|}
\hline Input variable & $\begin{array}{c}\mathrm{T} \\
\left({ }^{0} \mathrm{C}\right) \\
\left(X_{1}\right) \\
\end{array}$ & $\begin{array}{l}\mathrm{RH} \\
(\%) \\
\left(X_{2}\right) \\
\end{array}$ & $\begin{array}{c}\text { TOW } \\
\text { (hrs) } \\
\left(X_{3}\right) \\
\end{array}$ & $\begin{array}{c}C l^{-} \\
\left(\mathrm{mg} / \mathrm{m}^{2} . \text { day }\right) \\
\left(X_{4}\right)\end{array}$ & $\begin{array}{c}\mathrm{SO}_{2} \\
\left(\mathrm{mg} / \mathrm{m}^{2} . \text { day }\right) \\
\left(X_{5}\right)\end{array}$ & $\begin{array}{c}\mathrm{Rf} \\
(\mathrm{mm}) \\
\left(X_{6}\right) \\
\end{array}$ & $\begin{array}{l}\text { HoS } \\
(\mathrm{hrs}) \\
\left(X_{7}\right)\end{array}$ & $\begin{array}{c}K \\
\left(\mathrm{~g} / \mathrm{m}^{2)}\right. \\
\text { (Output) }\end{array}$ \\
\hline Min & 17.400 & 65.000 & 112.237 & 5.641 & 5.141 & 10.700 & 36.300 & 20.429 \\
\hline Mean & 25.538 & 82.042 & 445.408 & 12.886 & 8.197 & 213.079 & 146.242 & 22.830 \\
\hline Max & 32.800 & 91.000 & 618.809 & 25.854 & 10.566 & 1163.700 & 270.800 & 25.267 \\
\hline $\mathrm{SD}$ & 4.424 & 6.921 & 136.214 & 6.220 & 1.684 & 306.325 & 64.788 & 1.076 \\
\hline $\mathrm{COV}$ & 0.173 & 0.084 & 0.305 & 0.482 & 0.205 & 1.437 & 0.443 & 0.047 \\
\hline
\end{tabular}

the database used in this study was mostly focused on the tropical monsoon climate, where steel is the most susceptible to corrosion. Figure 1 presents the histogram of the used data samples. In addition, the relationships between the atmospheric corrosion rate of carbon steel and seven input parameters are represented by the correlation matrix, as described in Figure 2. Based on this figure, it can be found that some parameters had a strong correlation such as RH and TOW or T and HoS. It is attributed to the reason that the relative humidity is always accompanied by time of wetness, and temperature is associated with the sunshine hour. Meanwhile, some others were poorly correlated such as $\mathrm{Rf}$ and $\mathrm{SO}_{2}$ or TOW and $\mathrm{SO}_{2}$ since their physical meanings have no connection. Moreover, the correlation between each single input parameter and the output, $K$, appeared to be weak.

\section{Existing Empirical Equations, Regression, and ANN Models}

3.1. Existing Equations for Predicting the Atmospheric Corrosion Rate. In addition to regression models, the existing formulas for calculating the corrosion rate are presented in this study. Three typical formulas proposed by various studies $[19,21,25]$ were used to obtain the atmospheric corrosion rate of carbon steel. Table 2 summarizes the empirical equations for calculating the atmospheric corrosion rate of steel.

3.2. Regression Models. We also performed regression models to calculate the corrosion rate based on the used database. The regression is normally employed to define a relationship between variables. The regression model can be expressed by a general linear least-squares model as follows:

$$
\begin{aligned}
Y & =a_{0}+a_{1} z_{1}+a_{2} z_{2}+\cdots+a_{m} z_{m}+e, \\
& =[Z] \times[A]+[E]
\end{aligned}
$$

where $z_{1}, z_{2}, z_{m}$ are basis functions; $a_{0}, a_{1}, a_{2}, a_{m}$ represent the regression coefficients; $e$ is the residual, while $[E] \mathrm{de}-$ notes the residual matrix [39]; $[A]$ is the matrix determined by minimizing the mean squared difference between the regression values and the actual experimental data; $[Z]$ is the input parameter matrix; $A$ is the least-square estimate of $[A]$, and it is determined according to [40] and expressed as follows:

$$
\widehat{A}=\left[[Z]^{T}[Z]\right]\left\{[Z]^{T}[Y]\right\},
$$

where $[Z]^{T}$ is the transformation matrix of $[Z]$. This study has used linear, quadratic, and quadratic with mixed terms regression models for input data. A summary of the forms and coefficients of three regression models is presented in Table 3.

3.3. Proposed ANN Model. ANN is capable of dealing with various categories such as regression analysis, classification, or data processing $[41,42]$. Neurons are the smallest units in an ANN model. An ANN model comprises (1) an input layer, which contains input parameters, (2) single or multiple hidden layers, and (3) an output layer, which holds the output result. Neurons transfer signals to other neurons based on the signals they receive from other neurons. Thus, each neuron is connected to other neurons in the network through these synaptic connections, whose values are weighted. The signals transmitting through the network are strengthened or dampened by these weight values. It should be noted that there is a bias and an activation in each neuron [43]. The input signal of neuron is represented by a vector as $x=\left[x_{1}, x_{2}, \ldots, x_{m}\right]$, while the weighted sum of the input vector is determined by $z \in \mathbb{R}$, as shown in equation (7).

$$
z=\sum_{i=1}^{d} w_{i} x_{i}=w^{T} x+b
$$

where $w=\left[w_{1}, w_{2}, \ldots, w_{\mathrm{d}}\right] \in \mathbb{R}^{d}$ is the vector of weight in the $d$-dimension; $b$ denotes the bias.

An activation function in the network determines the transformation of the weighted sum of the input into an output from a node or nodes in a layer of the network. Activation functions also support normalizing the output of any input in the range $[1,-1]$ or $[0,1]$. The selection of activation functions is depending on the problem purpose. Some typical activation functions such as sigmoid and $\tan h$ forms can be used in the hidden layer of the recurrent neural network [44]. Since this study focuses on the prediction problem, the hyperbolic tangent sigmoid function, so-called tansig, and a linear activation function, namely, purelin, are employed, as expressed by equations (5) and (6). It should be noted that the tansig function is used in the hidden layer, while the purelin function is utilized in the output layer. Those functions were also used for training neural networks in previous studies [45-47]. 


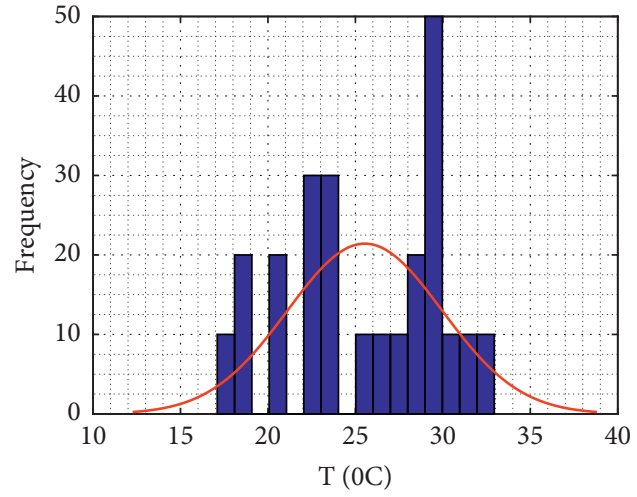

(a)

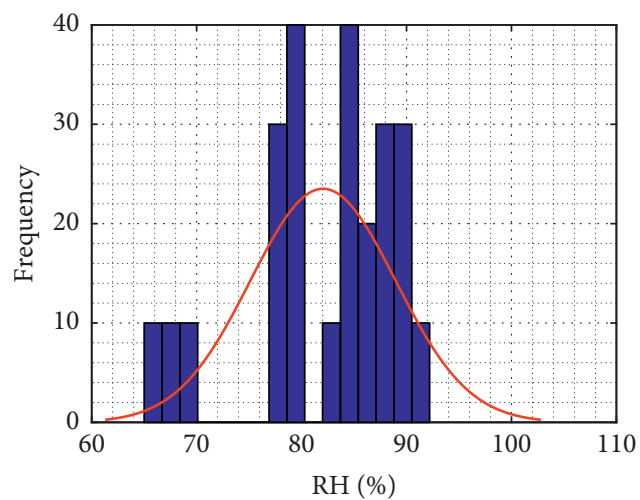

(c)

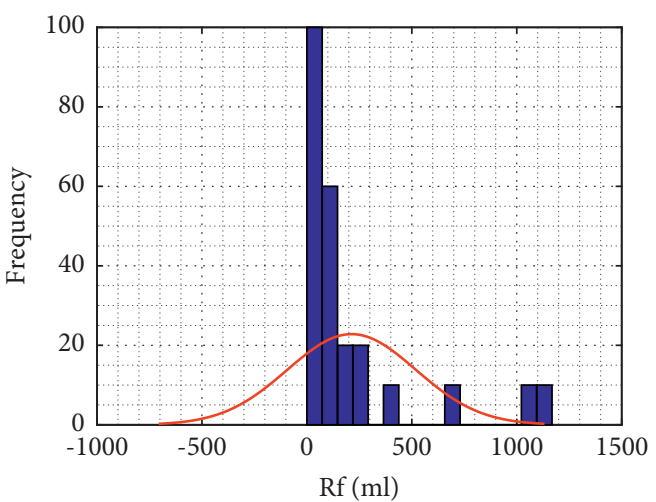

(e)

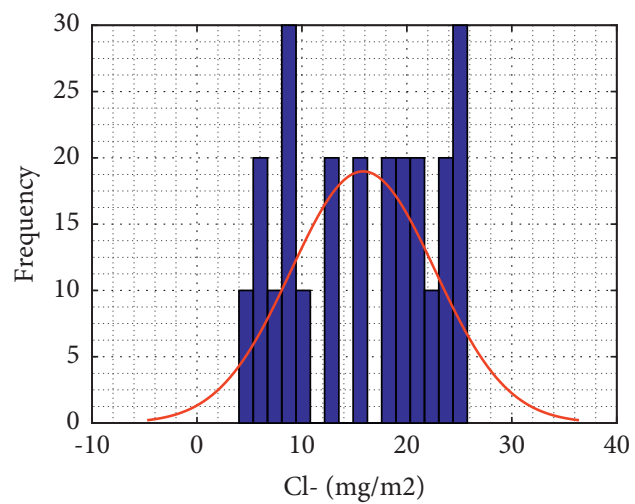

(g)

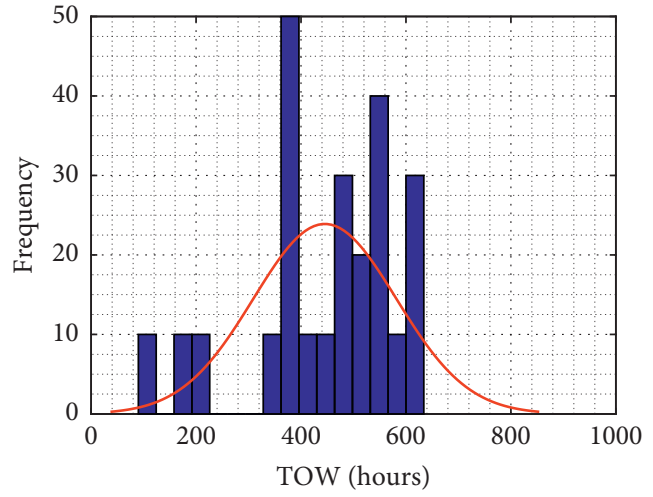

(b)

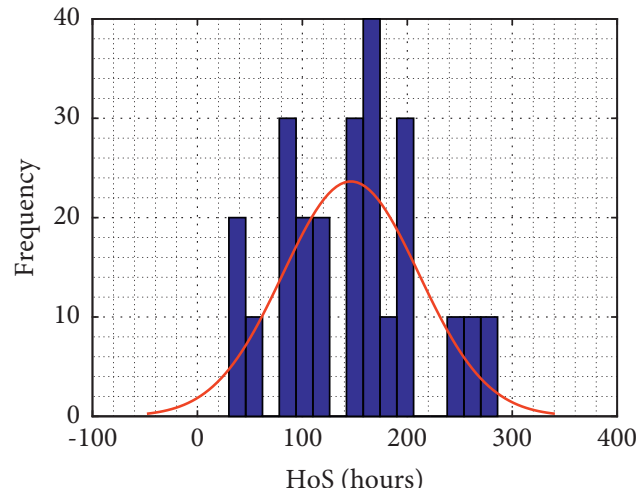

(d)

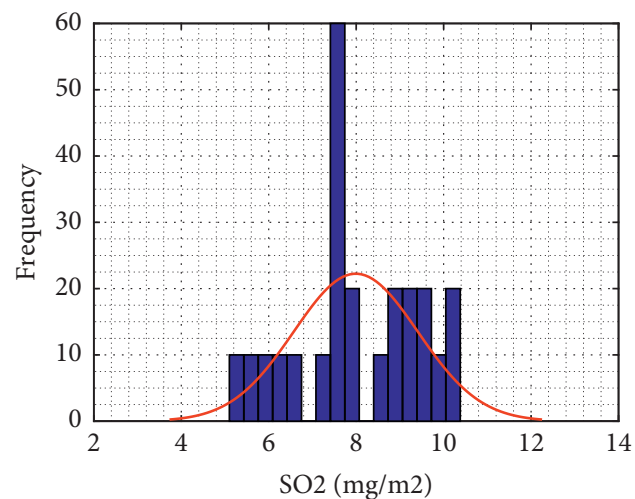

(f)

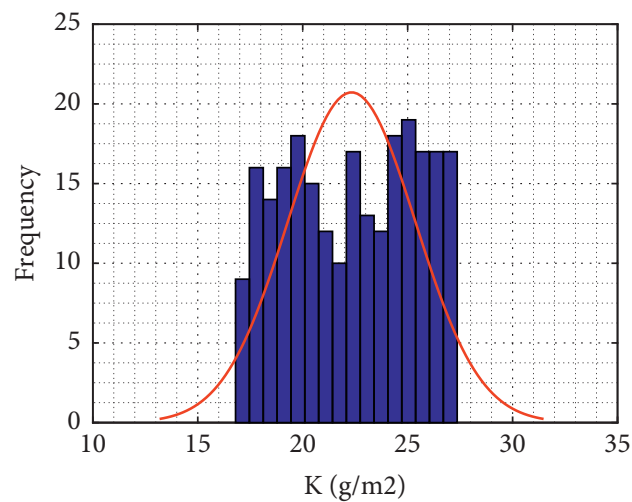

(h)

FIGURE 1: Histograms and normal distribution curves of experimental datasets (noting that the red curves represent the normal distribution of data). 


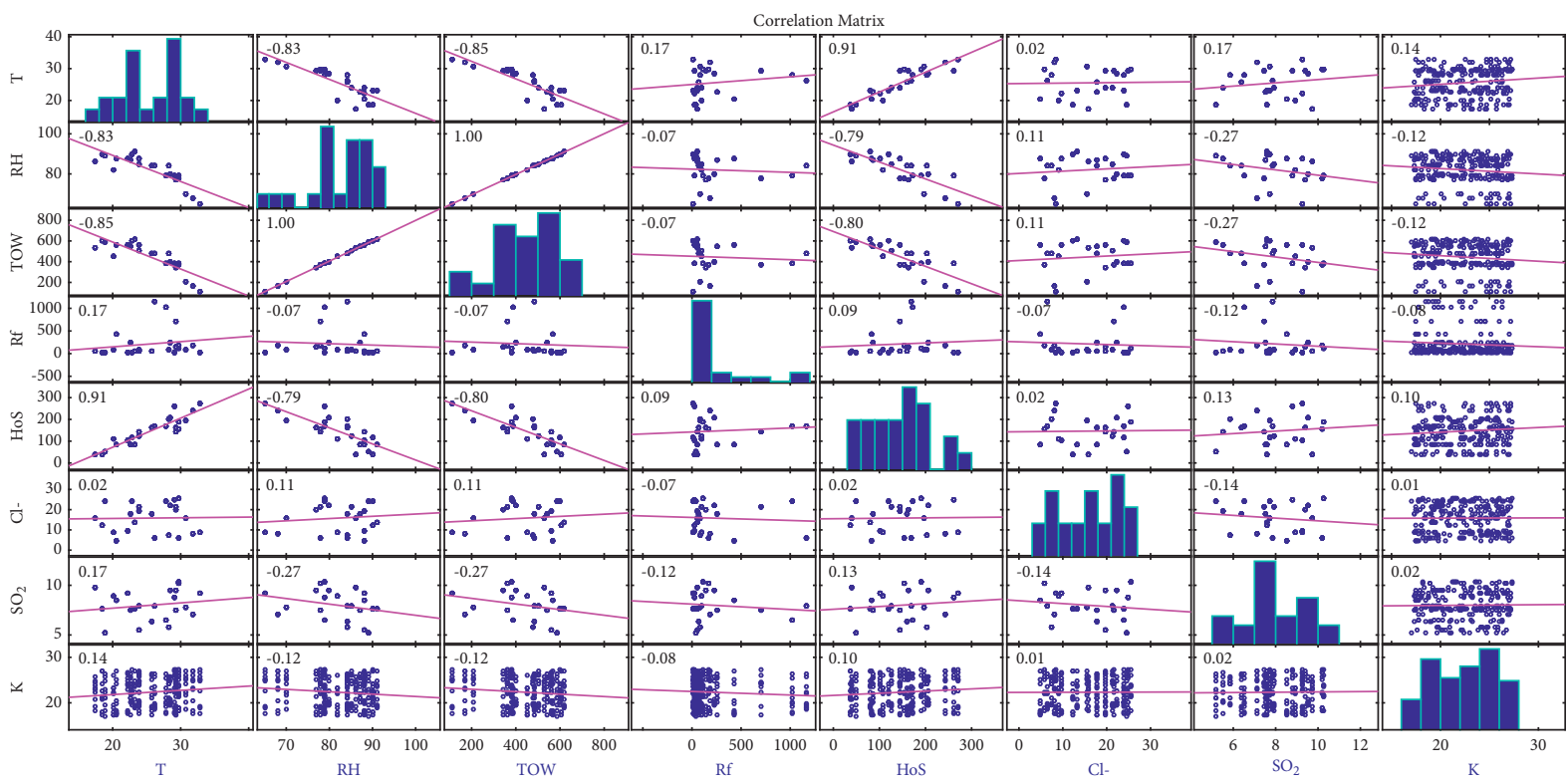

FIgURE 2: Correlation between input parameters in the dataset.

TABLE 2: Formulas for calculating the atmospheric corrosion rate of carbonic steel.

\begin{tabular}{lcc}
\hline Reference & Formulas \\
\hline Knotkova et al. [19] and Roberge et al. [21] & $K=1.327+0.4313\left(\mathrm{SO}_{2}\right)+0.1384\left(\mathrm{Cl}^{-}\right)+0.0057(\mathrm{TOW})$ & $(2)$ \\
ISOCORRAG [25] & $K=0.31\left(\mathrm{SO}_{2}\right)+0.57\left(\mathrm{Cl}^{-}\right)+0.31(\mathrm{TOW})$ & $(3)$ \\
MICAT [25] & $K=0.30\left(\mathrm{SO}_{2}\right)+0.69\left(\mathrm{Cl}^{-}\right)$ & $(4)$ \\
\hline
\end{tabular}

TABle 3: Forms and coefficients of three regression models.

\begin{tabular}{|c|c|c|}
\hline Regression model & Function type, $y$ & Regression coefficient \\
\hline First order (MLR1) & $a_{0}+a_{1} X_{1}+\cdots+a_{7} X_{7}$ & $\begin{array}{l}a_{0}=15.594, a_{1}=0.060, a_{2}=0.001 \\
a_{3}=0.334, a_{4}=0.041, a_{5}=0.275 \\
a_{6}=0.002, a_{7}=0.001, R^{2}=0.9330\end{array}$ \\
\hline Quadratic order (MLR2) & $\begin{array}{l}a_{0}+a_{1} X_{1}+\cdots+a_{7} X_{7}+ \\
+a_{11} X_{1}^{2}+a_{22} X_{2}^{2}+\cdots+a_{77} X_{7}^{2}\end{array}$ & $\begin{array}{l}a_{0}=81.698, a_{1}=0.194, a_{2}=0.001 \\
a_{3}=0.134, a_{4}=0.040, a_{5}=0.275 \\
a_{6}=0.018, a_{7}=0.001, a_{11}=0.001 \\
a_{22}=0.021, a_{33}=5.56 e-05, a_{44}=7.67 e-05 \\
a_{55}=5.66 e-03, a_{66}=-2.43 e-07, a_{77}=-9.86 e-06 \\
R^{2}=0.93345 .\end{array}$ \\
\hline Quadratic with mixed terms (MLR3) & $\begin{array}{l}a_{0}+a_{1} X_{1}+\cdots+a_{7} X_{7}+ \\
+a_{11} X_{1}^{2}+a_{22} X_{2}^{2}+\cdots+a_{77} X_{7}^{2}+ \\
+a_{12} X_{1} X_{2}+\cdots+a_{67} X_{6} X_{7}\end{array}$ & $\begin{array}{l}a_{0}=47.301, a_{1}=0.1 e-07, a_{2}=0.1 e-07 \\
a_{3}=0.1 e-07, a_{4}=0.1 e-07, a_{5}=0.1 e-07 \\
a_{6}=0.1 e-07, a_{7}=0.1 e-07, a_{11}=0.1 e-07 \\
a_{22}=0.1 e-07, a_{33}=0.1 e-05, a_{44}=0.008 \\
a_{55}=0.0, a_{66}=2.5 e-06, a_{77}=2.7 e-05 \\
a_{12}=-0.003, a_{13}=5.7 e-05, a_{14}=0.019 \\
a_{15}=0.0, a_{16}=-0.001, a_{17}=3.4 e-05 \\
a_{23}=-0.001, a_{24}=-0.017, a_{25}=0.022 \\
a_{26}=6.64 e-05, a_{27}=-0.002, a_{34}=1.62 e-04 \\
a_{35}=-0.002, a_{36}=-7.49 e-05, a_{37}=3.4 e-04 \\
a_{45}=0.0, a_{46}=2.94 e-05, a_{47}=8.23 e-05 \\
a_{56}=8.56 e-05, a_{57}=-0.005, a_{67}=-2.38 e-05 \\
R^{2}=0.93519\end{array}$ \\
\hline
\end{tabular}




$$
\begin{aligned}
& y=\operatorname{tansig}(x)=\frac{2}{1+e^{-2 x}}-1, \\
& y=\operatorname{purelin}(x)=x .
\end{aligned}
$$

According to Golafshani and Ashour [48], normalizing the database in a range of $[-1,1]$ before training is required. The normalization of input variables is determined by the following expression:

$$
x_{n}=2 \times \frac{\left(x-x_{\min }\right)}{\left(x_{\max }-x_{\min }\right)}-1,
$$

where $x$ is the considered input variable, $x_{n}$ is the normalization of variable, and $x_{\min }$ and $x_{\max }$ denote the minimum and maximum of the variable in the dataset, respectively.

For the proposed ANN model in this study, seven parameters, namely, $\mathrm{T}, \mathrm{RH}, \mathrm{Rf}, \mathrm{TOW}, \mathrm{HoS}, \mathrm{Cl}^{-}, \mathrm{SO}_{2}$, are considered as the input variables, whereas the atmospheric corrosion rate of carbon steel, $K$, is the output variable. The two following steps are implemented for training ANN model:

Step 1. The input signals, after entering into the input layer, are transferred through the connections, from the hidden layer to the output layer.

Step 2. The predicted result is obtained from the feedforward process; however, we need to minimize the error, which uses the mean square error (MSE) indicator. To diminish this error, the iteration is conducted till a convergence is obtained. This step is for minimizing the error and obtaining an optimal model. This procedure is called back-propagation. The MSE value is calculated using the following equation:

$$
\mathrm{MSE}=\frac{1}{n} \sum_{i=1}^{n}\left(p_{i}-t_{i}\right)^{2}
$$

where $n$ is the number of training data samples; $p_{i}$ and $t_{i}$ represent the predicted and target values of the $i^{t h}$ sample, respectively.

Overfitting describes the phenomenon of a model adapting too well to the training data such that it cannot predict unseen data samples well. Therefore, the model will fail to predict the output of data outside of the used training set. Accordingly, this phenomenon hinders the performance accuracy of the model and causes a deviation of the predicted result. To prevent such problem, the regularization solution is employed to modify the error function using the following equation [47, 49]:

$$
\text { MSEREG }=\gamma \mathrm{MSE}+(1-\gamma) \mathrm{MSWB},
$$

where $\gamma$ is the performance ratio; MSWB represents the mean squared network weights and biases, which is expressed as follows:

$$
\operatorname{MSWB}=\frac{1}{n} \sum_{j=1}^{n} \omega_{j}^{2} .
$$

To optimize the performance of the predictive model, an efficient ANN model has to be determined using trial-anderror process. Various ANN architectures were tested with the training ratio varying from 0.6 to 0.85 and a wide range of neuron numbers in the hidden layer. It should be noted that only one hidden layer was used in testing ANN models. In this study, the Levenberg-Marquardt (i.e., damped leastsquare) algorithm was utilized for regulating weights and biases of ANN models [50]. The advantages of this algorithm are solving nonlinear least-squares problems, robustness, and obtaining rapid convergence [51]. This algorithm was also widely used in previous studies [43, 46, 47, 52-55]. To assess the ANN models, two indicators, which are the $R^{2}$ value and MSE, were quantified. Accordingly, the optimum ANN model contains largest $R^{2}$ and smallest MSE after training process was chosen. It should be noted that the proportion, $70 \%, 15 \%$, and $15 \%$ of the dataset, was employed in training, testing, and validation, respectively.

The number of neurons in the hidden layer is an important factor to train the ANN model. The best ANN model for experimental data was achieved by a sensitivity analysis. The number of neurons in the hidden layer was varied from 5 to 21 to obtain the optimum ANN model. After performing the sensitivity analysis, the best model with 10 neurons in the hidden layer was chosen, as illustrated in Figure 3.

Figure 4 shows the structure of the proposed ANN model. In this model, seven neurons in the input layer denote the seven input variables (shown in Table 1), and one neuron in the output layer represents the atmospheric corrosion rate of carbon steel. It should be noted that the developed ANN model and its performance were conducted using MATLAB [56].

\section{Results and Discussion}

4.1. ANN Model Performance. The performance of the proposed ANN model is shown in Figure 5, in which MSE for training, validating, and testing decrease with an increment of the epoch. The best validation performance was selected since MSE was reduced to $1.7814 \times 10^{-3}$ at the $4^{\text {th }}$ epoch. A small value of the squared error indicates that the ANN model was well trained.

Figure 6 shows the regression of the developed ANN model, in which the output and target results are highly matched. The $R^{2}$ values for training, testing, validation, and all-data regression are 0.9998, 0.9998, 0.9999, and 0.9998, respectively. It is observed that the $R^{2}$ values were mostly close to unity, highlighting that the proposed ANN model has a good performance. In other words, the ANN model was highly reliable in predicting the atmospheric corrosion rate of carbon steel.

Figures 7-10 show the comparisons of the atmospheric corrosion rate of carbon steel obtained from the ANN model and numerical data for all-data, training, testing, and validation. The red lines in the left subfigures show the normalized $K$ values predicted based on the ANN model; meanwhile the blue lines demonstrate the measured values of all-data samples, training, testing, and validation sets. Moreover, the right subfigures describe the corresponding errors of the comparisons. The 


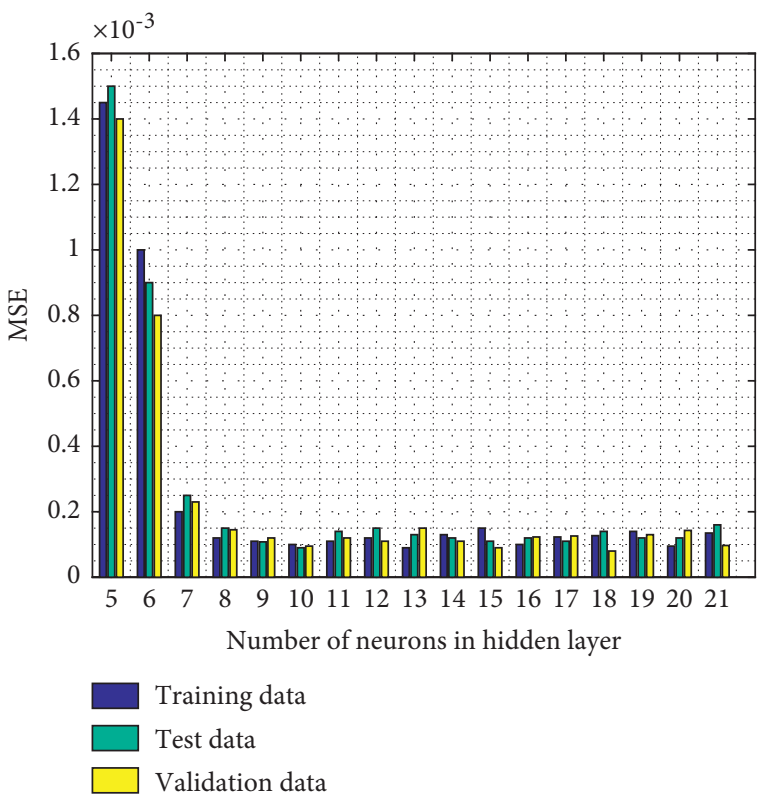

Figure 3: Number of neurons in hidden layer with the trainlm algorithm.

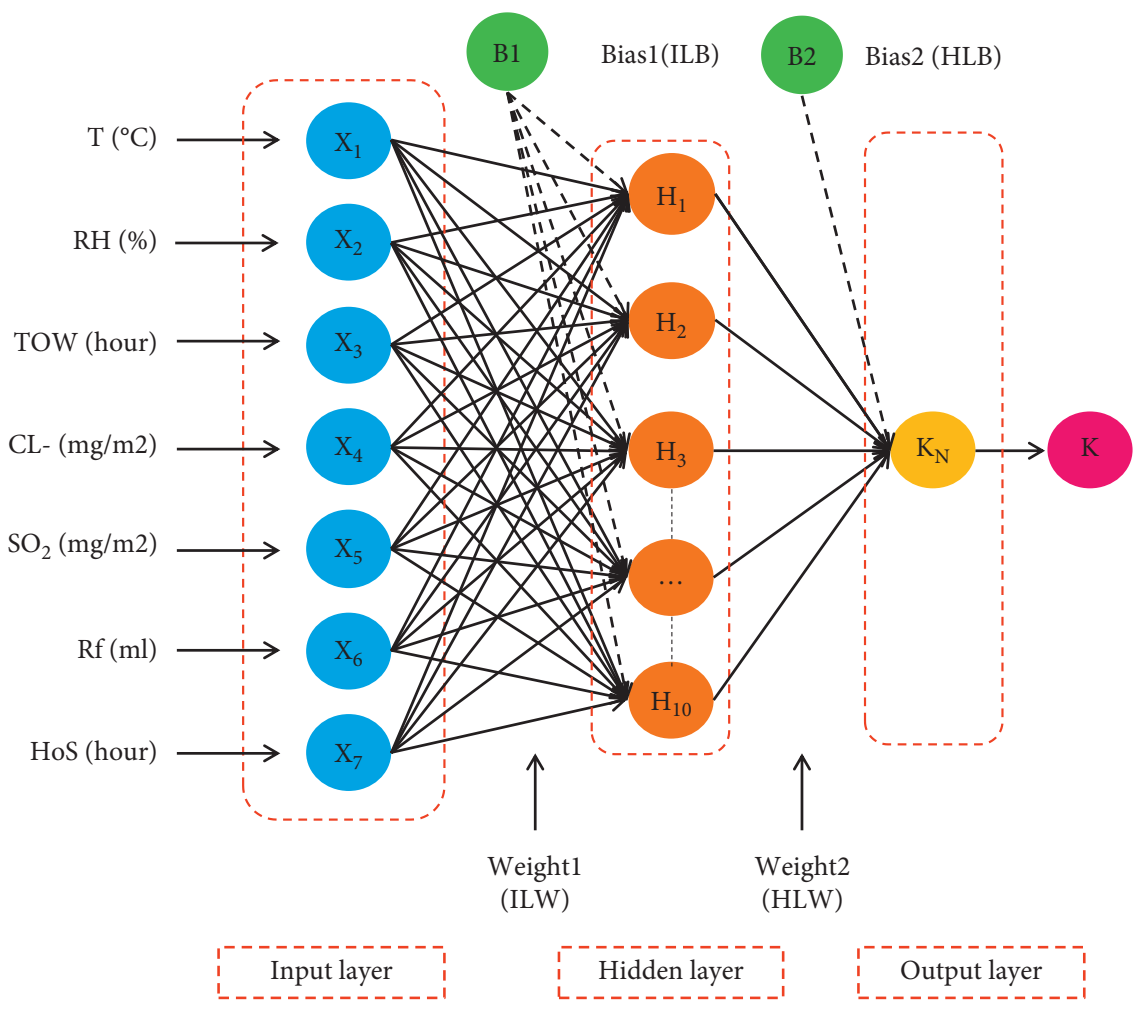

Figure 4: Structure of the proposed ANN model.

errors were shown to be trivial, mostly smaller than 0.08 . Again, it was demonstrated that the ANN model determined the atmospheric corrosion rate of carbon steel accurately. Even though the ANN performance results were compared with the validation dataset, cross-validation should be considered. However, due to the limitation of the developed algorithm, cross-validation was not performed in this study.
4.2. Comparison between the Developed ANN Model and Existing Formulas. The results obtained from the ANN model were compared with those of the regression models and existing formulas. Three regression models presented in Table 2 and existing formulas in Table 3 were utilized. To evaluate the performances of all predictive models, four indicators, which are RMSE, mean absolute percentage error 


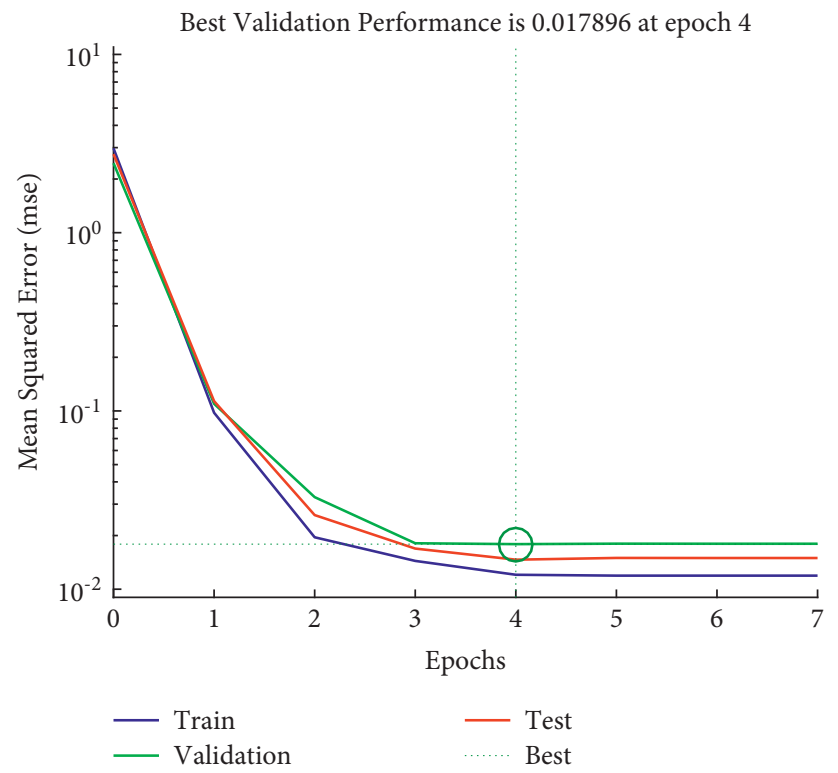

FIGURE 5: Iteration process for determining the best ANN model.

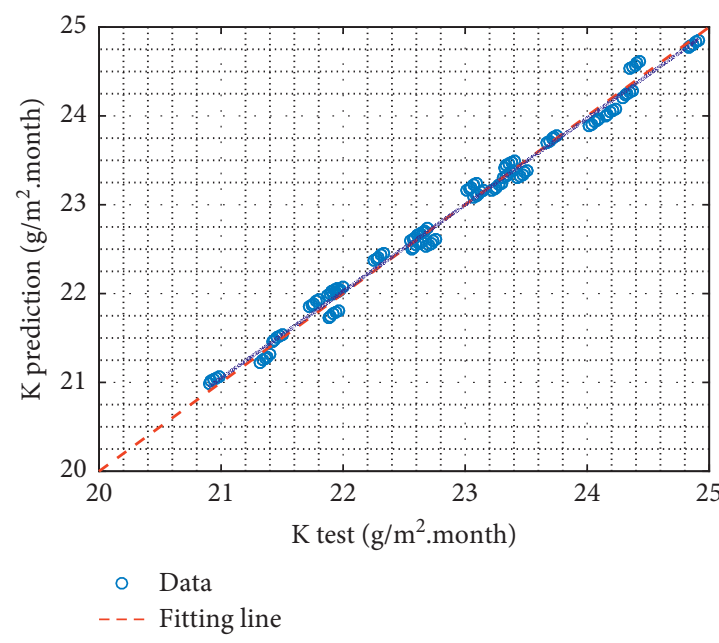

(a)

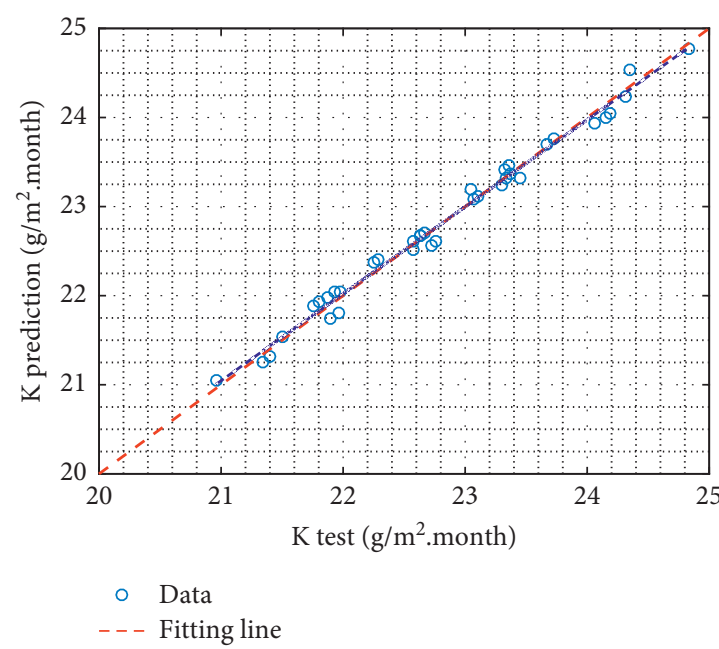

(c)

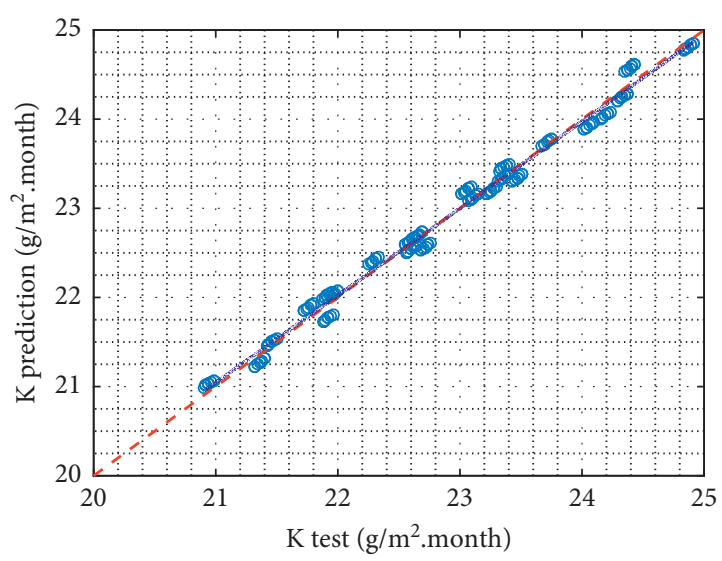

$\circ$ Data

- - - Fitting line

(b)

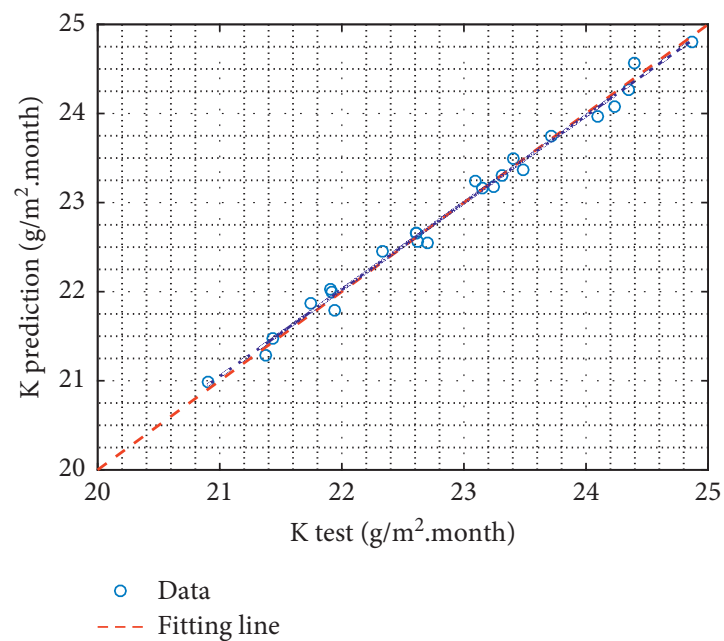

(d)

FIGURE 6: Regression results of the optimal ANN model. (a) All-data: $R^{2}=0.9998$. (b) Training: $R^{2}=0.9998$. (c) Validation: $R^{2}=0.9998$. (d) Testing: $R^{2}=0.9999$. 


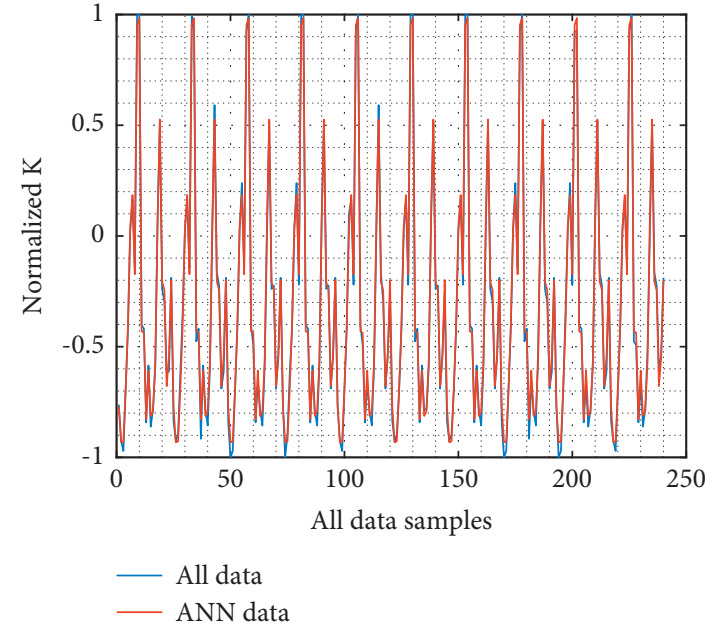

(a)

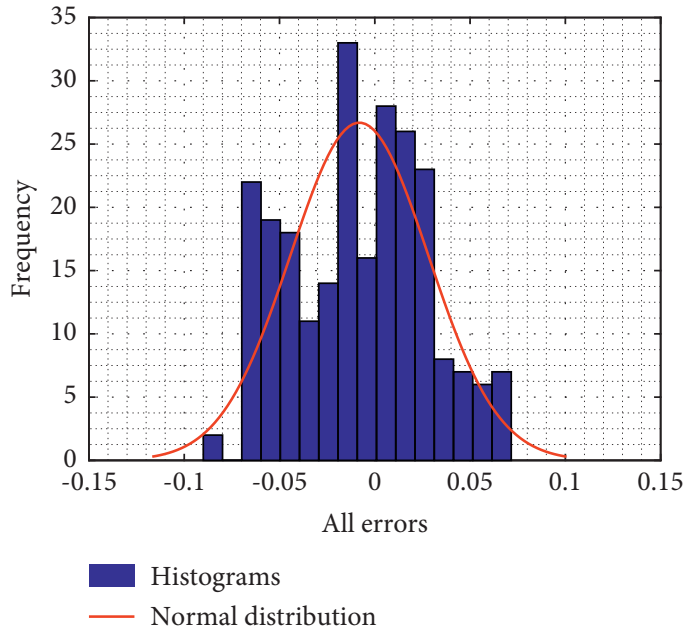

(b)

FIGURE 7: All-data performance.

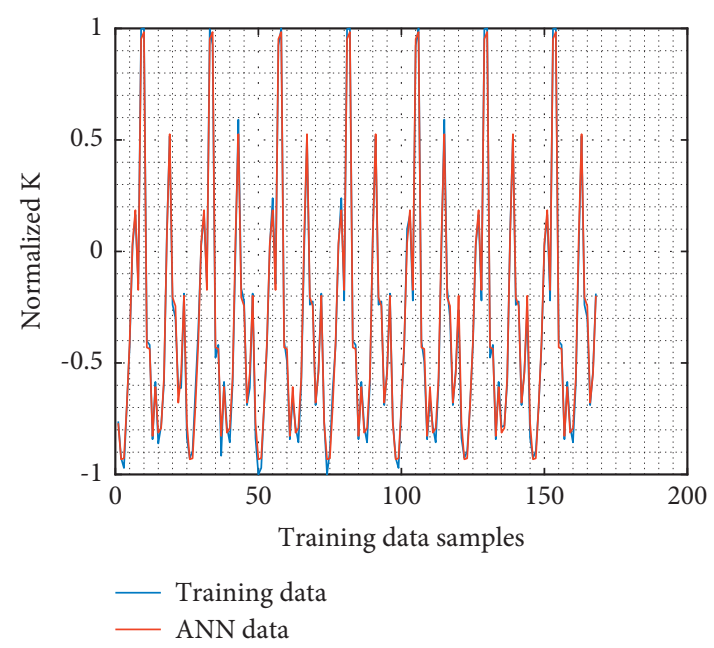

(a)

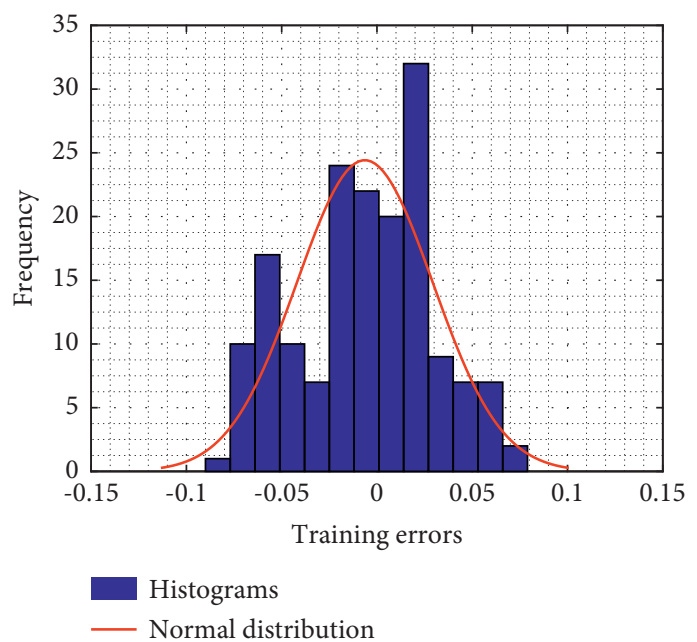

(b)

FIgURE 8: Training data performance.

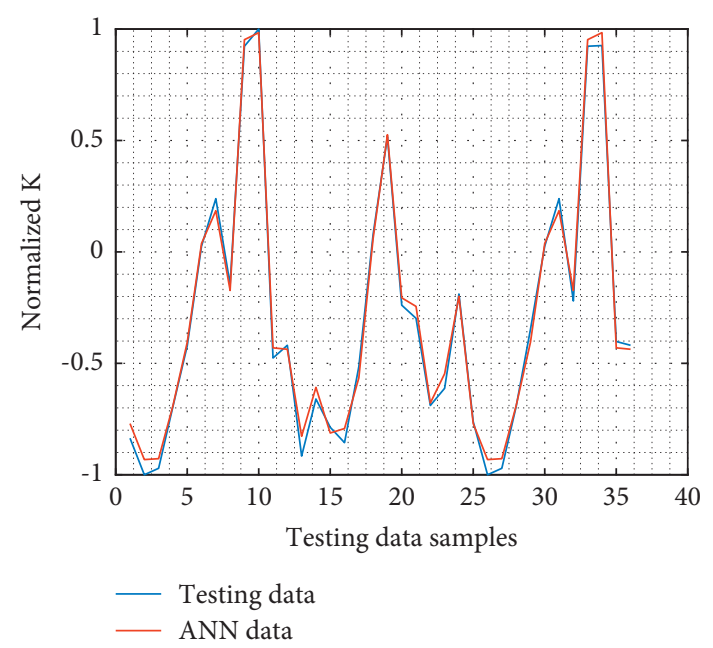

(a)

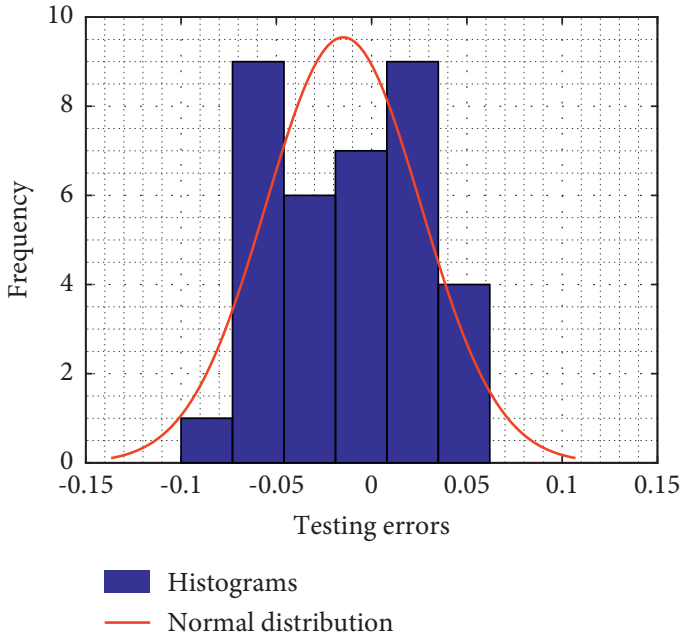

(b)

Figure 9: Testing data performance. 


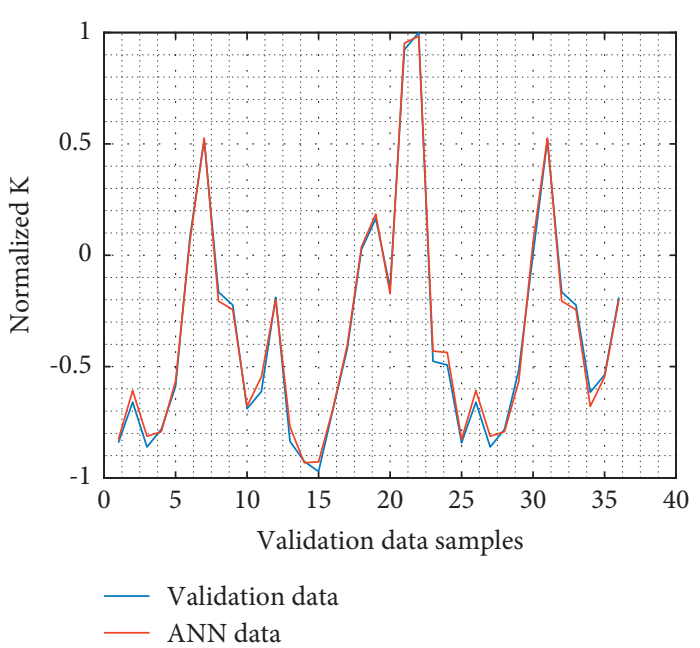

(a)

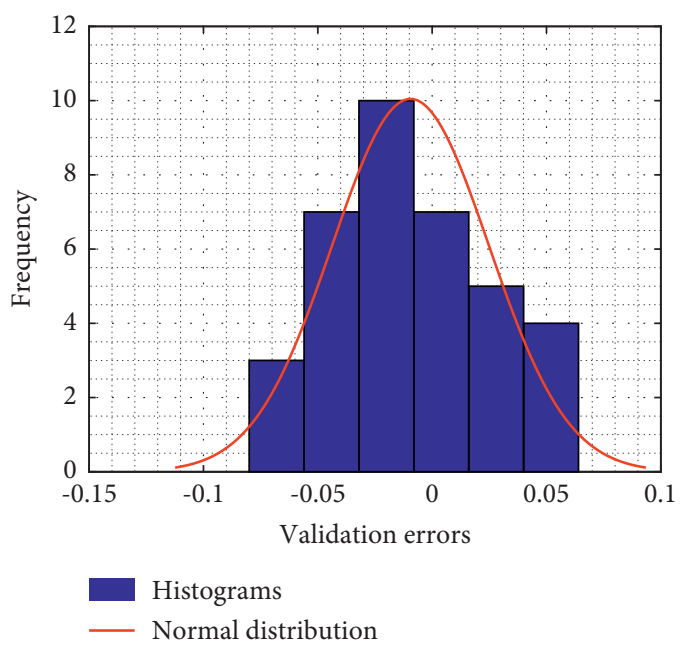

(b)

Figure 10: Validation data performance.

(MAPE), $R^{2}$, and Pearson correlation coefficient $(r)$, were employed. These indicators are calculated by the following equations:

$$
\begin{aligned}
\mathrm{RMSE} & =\sqrt{\left(\frac{1}{n}\right) \sum_{i=1}^{n}\left(t_{i}-o_{i}\right)^{2},} \\
\mathrm{MAPE} & =\frac{1}{n} \sum_{i=1}^{n}\left(\left|\frac{o_{i}-t_{i}}{o_{i}}\right| \times 100\right), \\
R^{2} & =1-\left(\frac{\sum_{i=1}^{n}\left(t_{i}-o_{i}\right)^{2}}{\sum_{i=1}^{n} o_{i}^{2}}\right), \\
r & =\frac{\sqrt{\left(n \sum t_{i} o_{i}\right)-\left(\sum t_{i}\right)\left(\sum o_{i}\right)}}{\sqrt{\left(n t_{i}^{2}-\left(\sqrt{t_{i}}\right)^{2}\right)\left(n \sum o_{i}^{2}-\left(\sqrt{o_{i}}\right)^{2}\right)}}
\end{aligned}
$$

where $t_{i}$ and $o_{i}$ are the target and output of the $i^{t h}$ sample, respectively; $n$ is the number of samples.

It should be noted that the RMSE and MAPE values represent the mean of errors, whereas, the $R^{2}$ and $r$ values were used to measure the variation and linear correlation between predicted and actual data, respectively. The higher values of $R^{2}$ and $r$ and the lower values of RMSE and MAPE indicate a good performance of the predictive model. If the predictive model is perfect, the values of $R^{2}$ and $r$ are equal to 1.0 , and the error is zero. Figure 11 shows the calculated values of statistical parameters with various predictive models. It is clear that the ANN model has the smallest values of RMSE and MAPE and largest values of $R^{2}$ and $r$, followed by quadratic regression models. In other words, the ANN model is superior in predicting the corrosion rate of carbon steel compared to the other models. Moreover, an overall performance of all predictive models is illustrated in Figure 12. Again, it is observed that the proposed ANN model contains the smallest standard deviation, followed by the regression models and predictive models proposed by
Knotkova et al. [19], Roberge et al. [21], and ISO and MICAT [25]. Details of the calculated results can be seen in Table 4.

Table 5 also shows the statistical results of different ratios of the predictive models to test results. It demonstrates that the mean ratio of the ANN model was 1.0002, mostly equal to unity, and the standard deviation was lowest compared to those of other models. Again, the ANN model was shown to be the optimal and reliable option in predicting the corrosion rate of carbon steel.

\section{Evaluation of the Effects of Input Parameters}

A parametric study was carried out to evaluate the influences of input parameters on the atmospheric corrosion rate of carbon steel using the developed ANN model. To account for the interaction of multiple parameters on calculated $K$, the considered variable was varied from the lowest to the highest range, and simultaneously other variables were changed in turn. It should be noted that the L, ML, M, MH, and H letters in Table 6 are the abbreviations of the lowest, middle-low, mean, middle-high, and highest values, respectively. Consequently, the variations of the predicted result caused by the variation of the input parameters were quantified.

5.1. Effect of the Average Temperature. Figure 13 shows the effects of the average temperature (i.e., $X_{1}$ ) on the atmospheric corrosion rate of carbon steel, $K$. During the variation of the average temperature $T$, other parameters were varied in turn to evaluate the effects of the interaction between $T$ and other variables on $K$. It was found that the increment of the average temperature caused an increase in the atmospheric corrosion rate of carbon steel. If $T$ was 1.5 times increased, the $K$ value was increased by $10 \%$. This observation can be attributed to the reason that the increment of temperature can intensify the chemical reaction, which may boost the corrosion process in the carbon steel. 


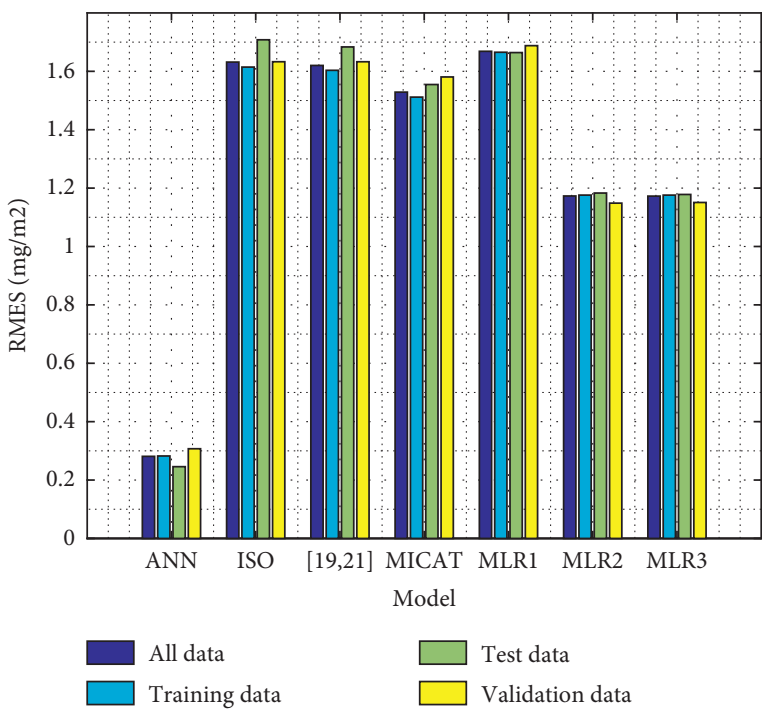

(a)

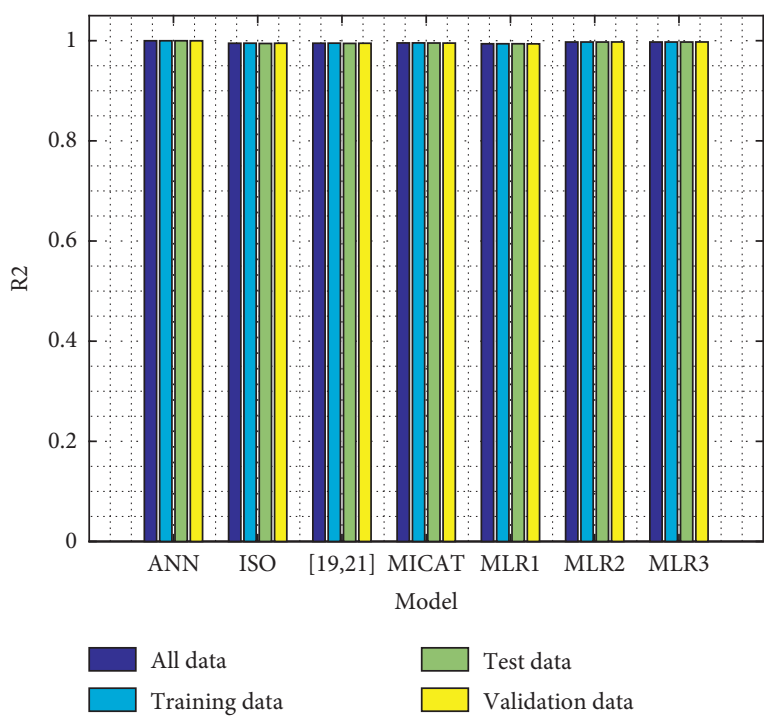

(c)

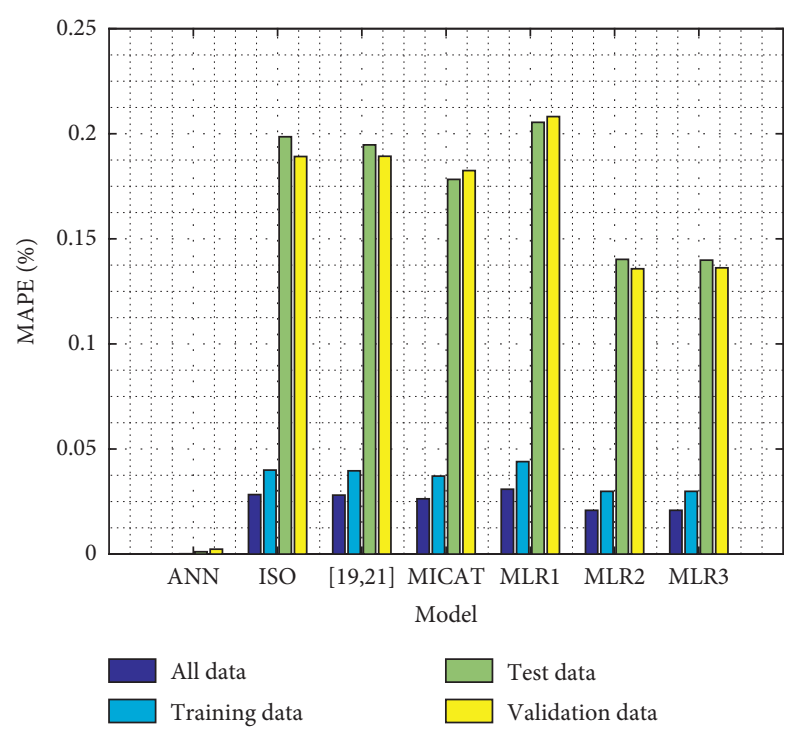

(b)

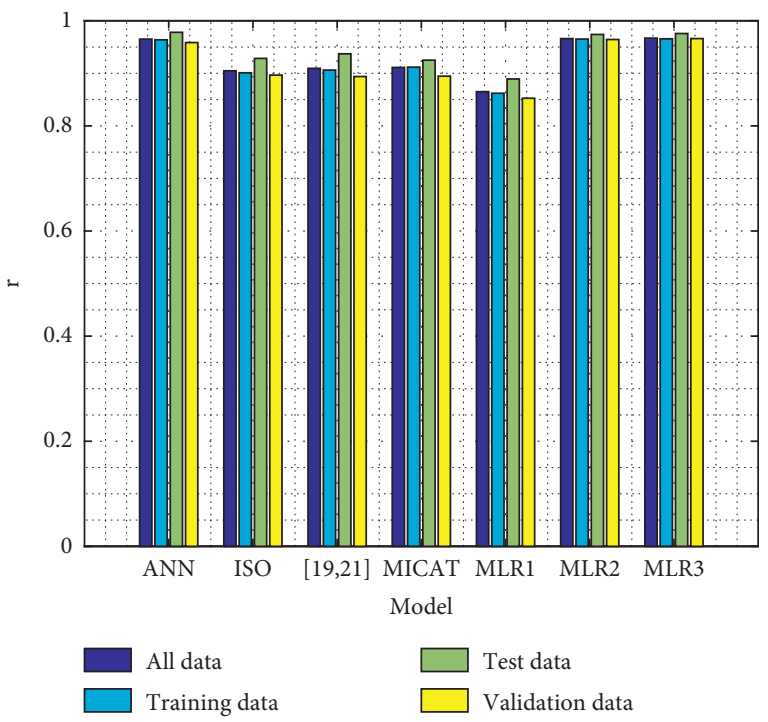

(d)

FIGURE 11: Calculated statistical parameters of predicted models.

5.2. Effect of the Average Relative Humidity. The effects of the average relative humidity (i.e., $X_{2}$ ) on the atmospheric corrosion rate of carbon steel are shown in Figure 14. The corrosion rate was gradually increased when the average relative humidity increased in all cases. Specifically, the corrosion rate was not affected by relative humidity at low temperature, short time of wetness, low level of $\mathrm{SO}_{2}$, and short time of sunshine.

5.3. Effect of the Time of Wetness. The time of wetness (i.e., $X_{3}$ ) depends on the temperature, humidity, total rainfall, and hours of sunshine. TOW had been identified according to the suggestion of Tidblad and Mikhailov [57]. The effects of TOW on the atmospheric corrosion rate of carbon steel are shown in Figure 15. Similar to T, the corrosion rate $K$ value was enlarged as TOW increased. This is consistent with the previous study [35].
5.4. Effect of the Average Chloride. The effects of the average chloride (i.e., $X_{4}$ ) on the atmospheric corrosion rate of carbon steel are shown in Figure 16. It was found that the corrosion rate was increased with the increment of $\mathrm{Cl}^{-}$. It can be attributed to the reason that the passivation film of steel can be damaged by chloride ions in the process of competing with hydrogen and oxygen ions in the absorption process, thus causing the occurrence of pitting corrosion [58].

\subsection{Effect of the Average Sulfur Dioxide Deposition Rate.} Figure 17 shows the effects of the average sulfur dioxide deposition rate (i.e., $X_{5}$ ) on the atmospheric corrosion rate of carbon steel. The atmospheric corrosion rate of carbon steel increased as the $\mathrm{SO}_{2}$ rate increased. This is due to the attribution of $\mathrm{SO}_{2}$ to react with $\mathrm{H}_{2} \mathrm{SO}_{4}$ in the atmosphere or on 


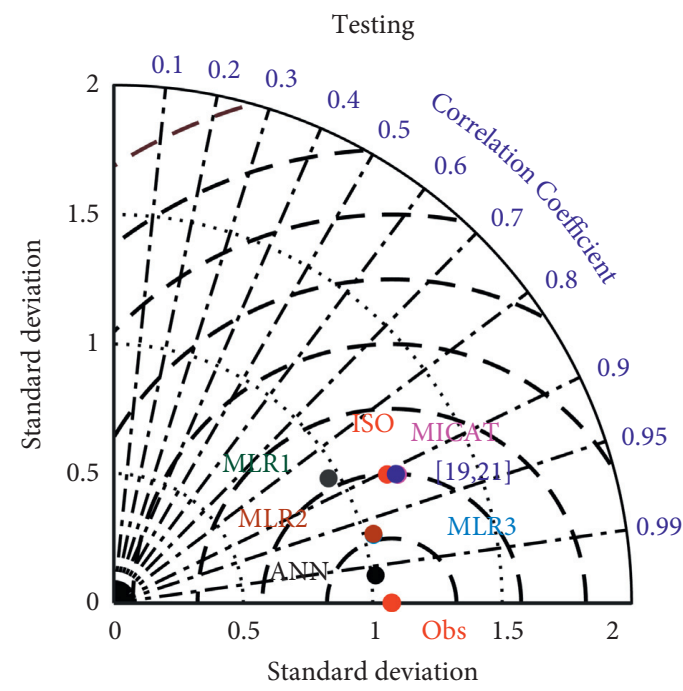

Figure 12: Taylor diagram for testing data with different predictive models.

the surface of carbon steel. Combining with high humidity or wetness, the damage caused by $\mathrm{SO}_{2}$ would be considerable [59].

5.6. Effect of the Total Rainfall. Figure 18 shows the influences of the total rainfall (i.e., $X_{6}$ ) on the atmospheric corrosion rate. It can be observed that the atmospheric corrosion rate of carbon steel was increased, since $\mathrm{Rf}$ varied from the minimum to the maximum value. Moreover, the $K$ value was increased by $6 \%$ if the total rainfall increased 6 times. In the tropical climate region, due to the annual high rainfall, a consideration of the effects of rainfall on the corrosion rate is needed. This statement was also pointed out in previous studies $[30,60]$.

5.7. Effect of the Hours of Sunshine. Figure 19 shows the effects of the hours of sunshine (i.e., $X_{7}$ ) on the atmospheric corrosion rate of carbon steel. It was found that the atmospheric corrosion rate was decreased with an increment of HoS. This observation is probably due to the reason that the sunshine hours have a strongly negative correlation with the relative humidity and time of wetness, as shown in Figure 2. Moreover, the corrosion mechanism of carbon steel in the tropical region is a complex combination of chemical and physical conditions.

Figure 20 demonstrates the sensitivity of input variables to the atmospheric corrosion rate of carbon steel. It should be noted that the $K$ value in this figure was achieved at the upper bound (i.e., maximum) of each input parameter. It was observed that the rainfall was the most influential parameter on predicting the atmospheric corrosion rate, followed by the time of wetness, the average temperature, the average sulfur dioxide deposition rate, the average chloride, and average relative humidity. Meanwhile, the sunshine duration negatively affected the atmospheric corrosion rate.

\section{Practical Tools for the Atmospheric Corrosion Rate of Carbon Steel}

6.1. ANN Model-Based Equation. As analyzed above, the proposed ANN model can predict the atmospheric corrosion rate of carbon steel accurately. It is needed to develop an ANN-based formula for explicit usage in the practical problems. Considering the $K$ value as the output response, the procedures presented in the previous sections were adopted herein. The explicit formulation of $K$ was obtained directly from the developed ANN model by using the activation functions, weights, biases, and normalization factors, expressed as

$$
K=2.419 \times\left(K_{N}+1\right)+20.429
$$

where $K_{N}$ is a normalized atmospheric corrosion rate of carbon steel. The form of equation (12) comes from the denormalization procedure of equation (3). As a result, the value of 20.429 is the minimum value of the atmospheric corrosion rate of the database. The value of 2.419 is a half of the difference of maximum and minimum atmospheric corrosion rate values of database, as shown in Table 1 . The normalized value $K_{N}$ was a function, which is expressed by the following equation:

$$
\begin{aligned}
& K_{N}=h_{0}+\sum_{i=1}^{n} h_{i} H_{i}, \\
& H_{i}=\tanh \left(c_{i o}+c_{i 1} X_{1}+c_{i 2} X_{2}+c_{i 3} X_{3}+c_{i 4} X_{4}+c_{i 5} X_{5}+c_{i 6} X_{6}+c_{i 7} X_{7}\right),
\end{aligned}
$$




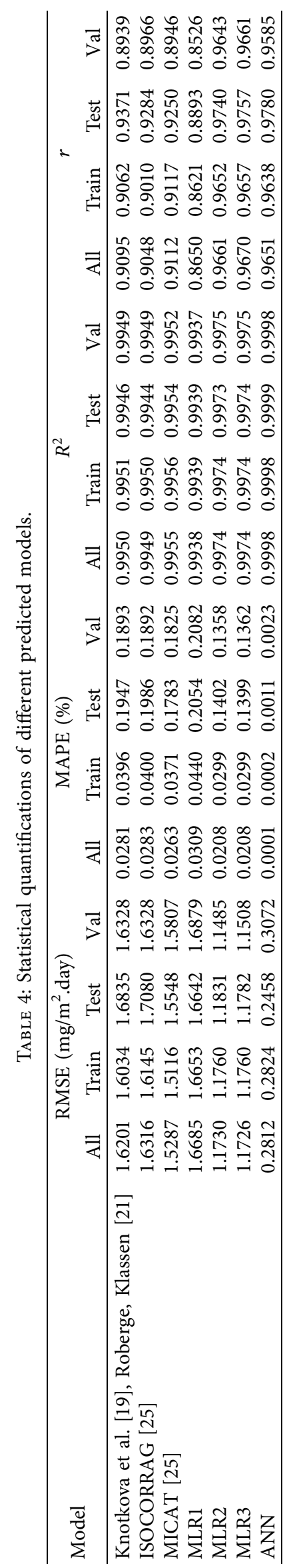


TABLe 5: Statistical characteristics of different predicted models, in which they are normalized with the test result.

\begin{tabular}{|c|c|c|c|c|c|c|c|}
\hline Parameter & Knotkova/test & ISO/test & MICAT/test & MLR1/test & MLR2/test & MLR3/test & ANN/test \\
\hline Mean & 0.9323 & 0.9318 & 0.9365 & 0.9312 & 1.0007 & 1.0005 & 1.0002 \\
\hline Standard deviation & 0.0223 & 0.0220 & 0.0223 & 0.0225 & 0.0122 & 0.0121 & 0.0121 \\
\hline Coefficient of variation & 0.0005 & 0.0005 & 0.0005 & 0.0005 & 0.0001 & 0.0001 & 0.0001 \\
\hline
\end{tabular}

TABLE 6: The variation range of input parameters.

\begin{tabular}{|c|c|c|c|c|c|}
\hline Input parameters & $\mathrm{L}$ & ML & $\mathrm{M}$ & $\mathrm{MH}$ & $\mathrm{H}$ \\
\hline $\mathrm{T}\left({ }^{\circ} \mathrm{C}\right)\left(X_{1}\right)$ & 17.400 & 21.469 & 25.538 & 29.169 & 32.800 \\
\hline $\mathrm{RH}(\%)\left(X_{2}\right)$ & 65.000 & 73.521 & 82.042 & 86.521 & 91.000 \\
\hline TOW (hrs) $\left(X_{3}\right)$ & 112.237 & 278.823 & 445.408 & 532.109 & 618.809 \\
\hline $\mathrm{Cl}^{-}$(mg/m².day) $\left(X_{4}\right)$ & 5.641 & 9.263 & 12.886 & 19.370 & 25.854 \\
\hline $\mathrm{SO}_{2}\left(\mathrm{mg} / \mathrm{m}^{2}\right.$.day $)\left(X_{5}\right)$ & 5.141 & 6.669 & 8.197 & 9.382 & 10.566 \\
\hline $\operatorname{Rf}(\mathrm{mm})\left(X_{6}\right)$ & 10.700 & 111.890 & 213.079 & 688.390 & 1163.700 \\
\hline $\operatorname{HoS}(\mathrm{hrs})\left(X_{7}\right)$ & 36.300 & 91.271 & 146.242 & 208.521 & 270.800 \\
\hline
\end{tabular}

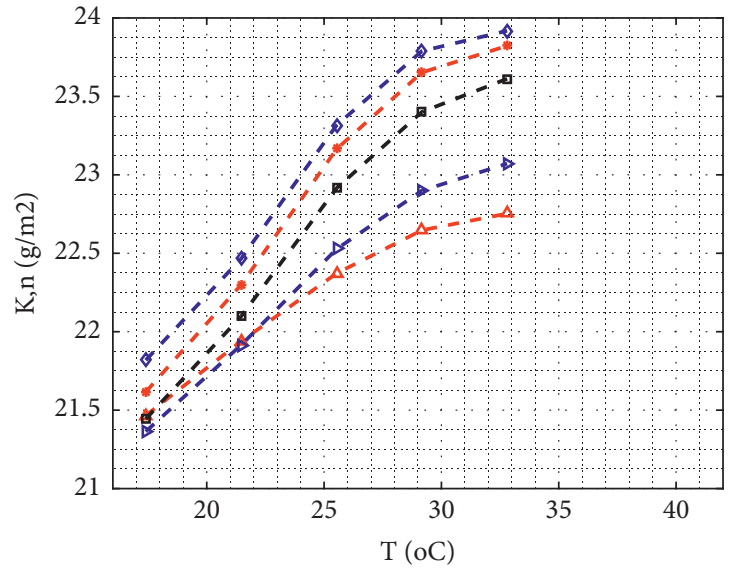

$$
\begin{aligned}
& -\Delta-\mathrm{RH}=65.000 \\
& -\triangleright-\mathrm{RH}=73.521
\end{aligned}
$$$$
\text { - }-\mathrm{RH}=82.042
$$

(a)

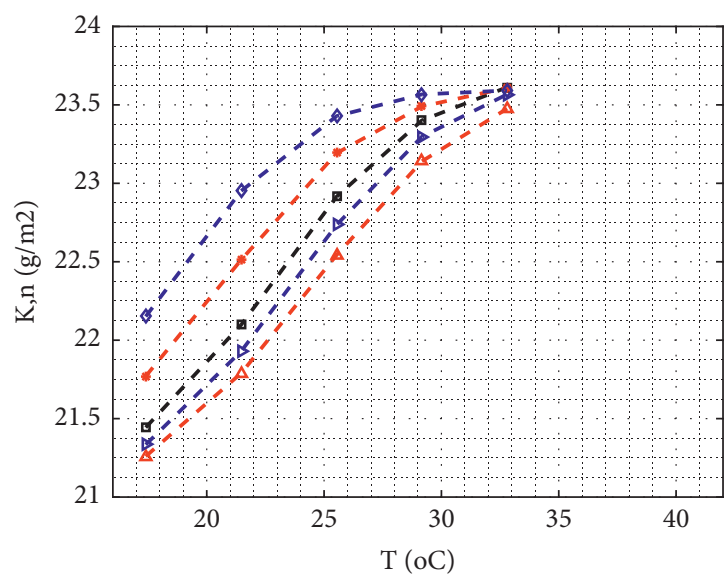

$-\leadsto-C L-=5.641$
$-\triangleright-C L-=9.263$
- - CL- $=12.886$

$$
\text { - - CL- }=19.370
$$$$
-\diamond-\mathrm{CL}-=25.854
$$

(c)

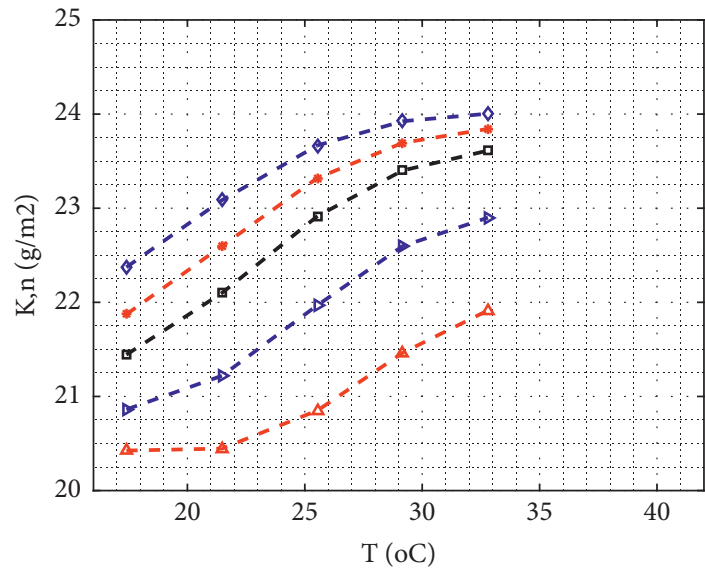

$$
\begin{aligned}
& -\Delta-\text { TOW }=112.237 \quad-*-\text { TOW }=532.109 \\
& \rightarrow-\text { TOW }=278.823 \\
& \text { - } \text { - } \mathrm{TOW}=445.408 \\
& -\diamond-\text { TOW }=618.809
\end{aligned}
$$

(b)

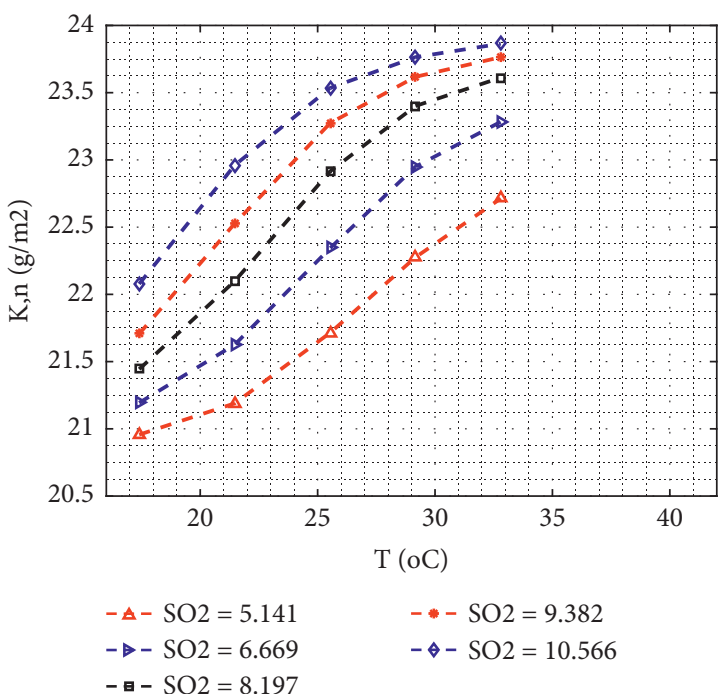

(d)

Figure 13: Continued. 


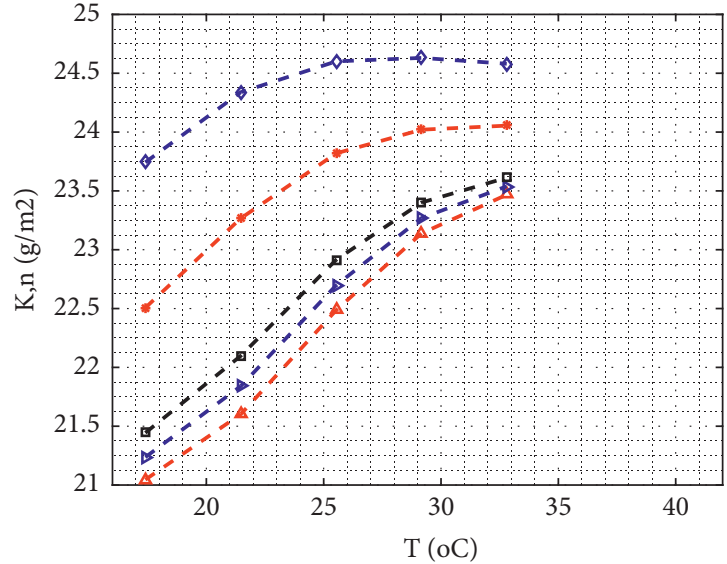

$$
\begin{array}{ll}
-\Delta-\mathrm{Rf}=10.700 & -\bullet-\mathrm{Rf}=688.390 \\
-\diamond-\mathrm{Rf}=111.890 & -\diamond-\mathrm{Rf}=1163.700 \\
\text {-в- Rf }=213.079 &
\end{array}
$$

(e)

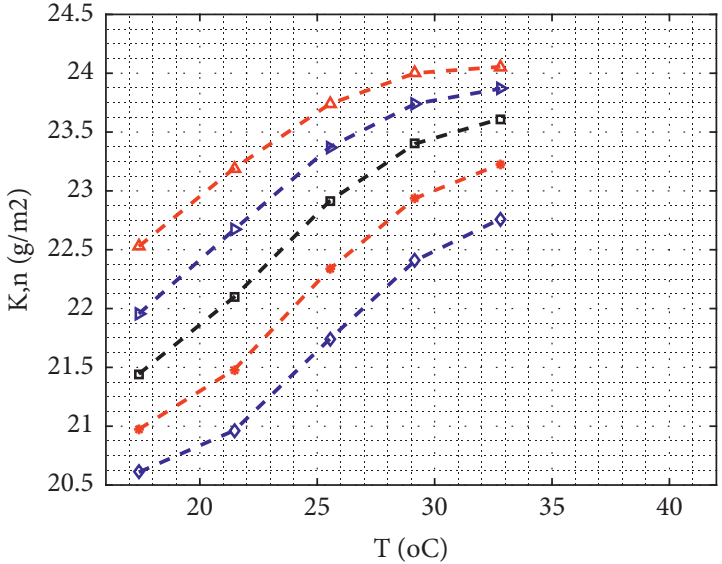

$$
\begin{array}{ll}
\text { - }-\mathrm{HoS}=36.300 & --\mathrm{HoS}=208.521 \\
\text { - }-\mathrm{HoS}=91.271 & -\diamond-\mathrm{HoS}=270.800 \\
\text { - }-\mathrm{H}-\mathrm{HoS}=146.242 &
\end{array}
$$

(f)

FiguRE 13: Effects of the average temperature.

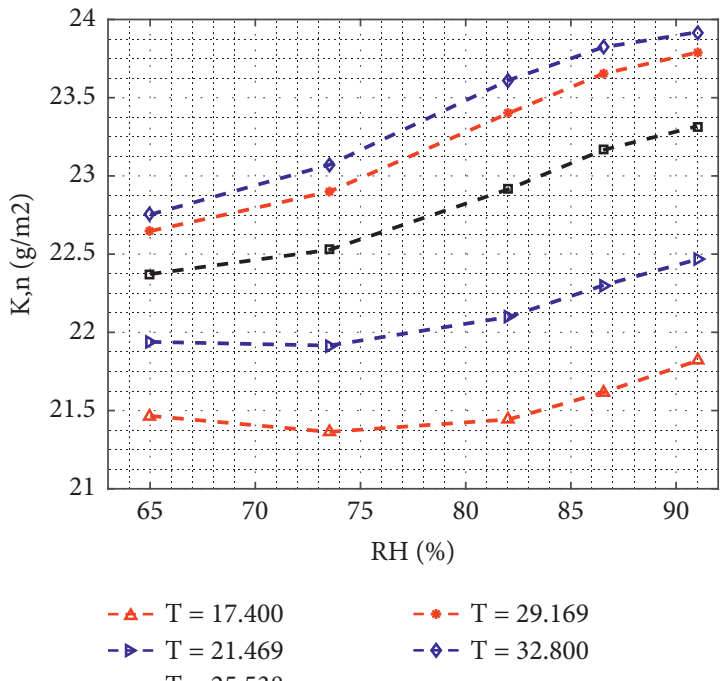

(a)

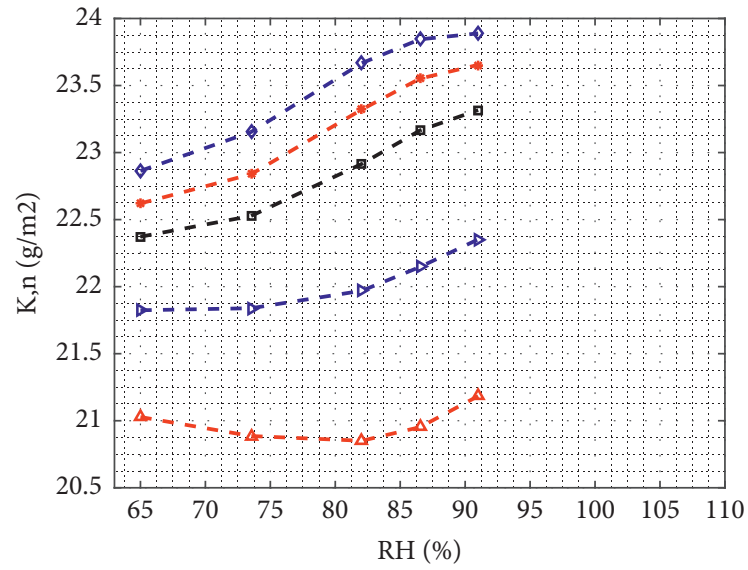

$$
\begin{array}{ll}
\text { - }- \text { TOW }=112.237 & -- \text { TOW }=532.109 \\
\text { - }- \text { TOW }=278.823 & -\diamond-\text { TOW }=618.809 \\
\text { - }- \text { TOW }=445.408 &
\end{array}
$$

(b)

Figure 14: Continued. 


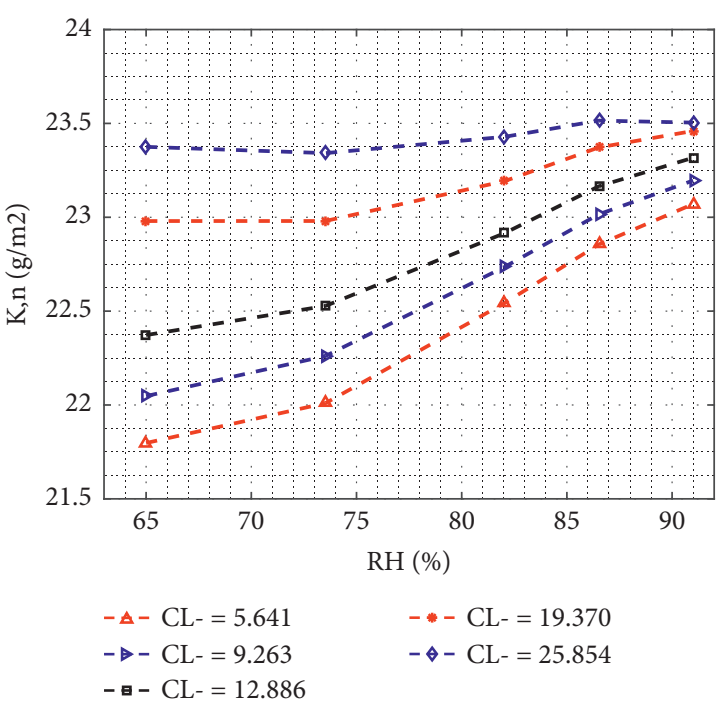

(c)

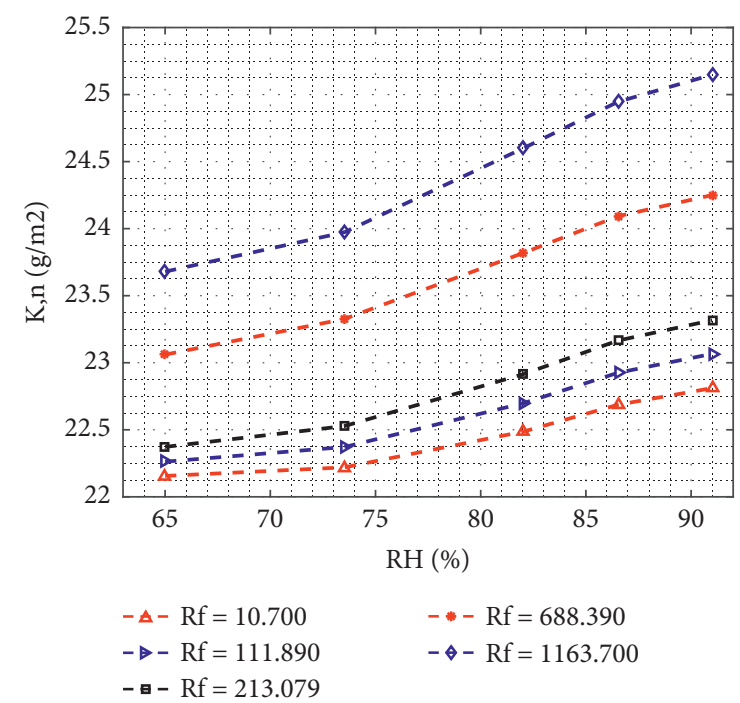

(e)

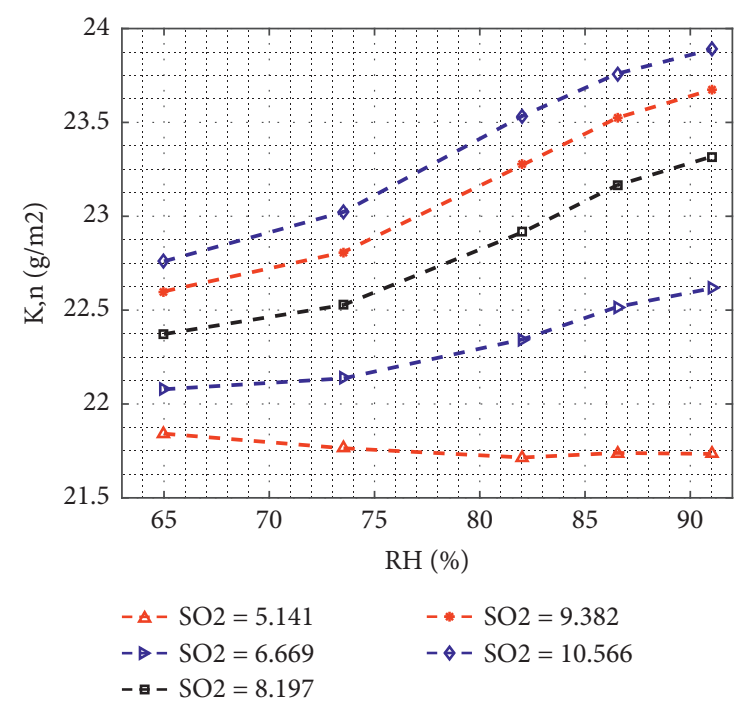

(d)

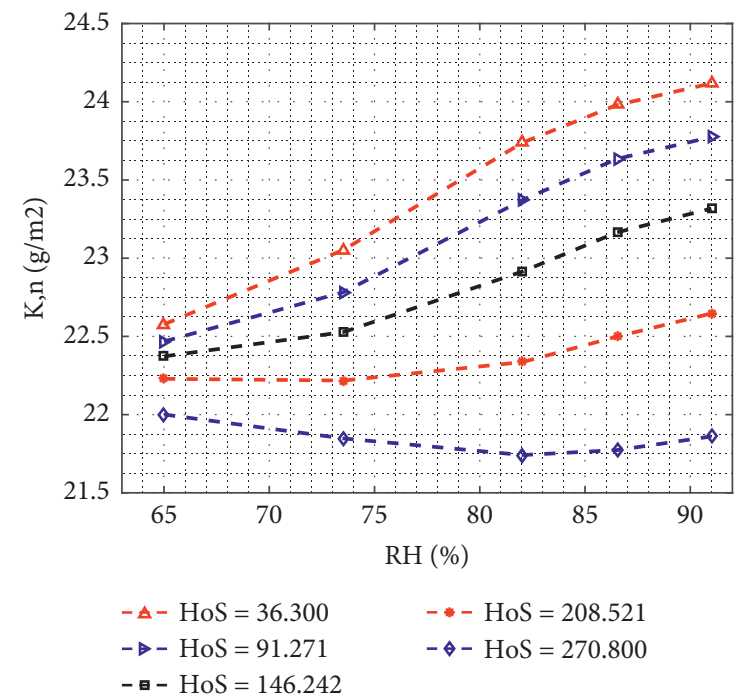

(f)

FIgURE 14: Effect of the average relative humidity.

where $n=10$ is the number of neurons in the hidden layer of developed ANN model. The other coefficients, $h_{0}$ to $h_{n}$ and $c_{i o}$ to $c_{i 7}$, are presented in Table 7 .

6.2. ANN Interactive Graphical User Interface (GUI). In this study, a practical GUI tool was constructed using MATLAB [56] to simplify calculating the atmospheric corrosion rate of carbon steel, as shown in Figure 21. Seven input parameters, from $X_{1}$ to $X_{7}$, were provided in the input signal. Also, ten neurons in the hidden layer are shown in Figure 21. This tool is accessed freely, and it is very convenient to use. Users can easily obtain the output by clicking on the "Start Predict" button after putting all input parameters. It takes less than one second to obtain the result. Since this GUI tool was developed using the proposed ANN model, the accuracy of prediction was verified and demonstrated in the previous section. This GUI tool is freely available at https://github.com/duyduan1304/GUI_corrosionrate.

It should be noted that the ANN algorithm cannot tackle extrapolation; thus the input values should be restricted to the minimum and maximum of the utilized database. To expand the coverage of ANN model, a wide range of collected data should be considered. 

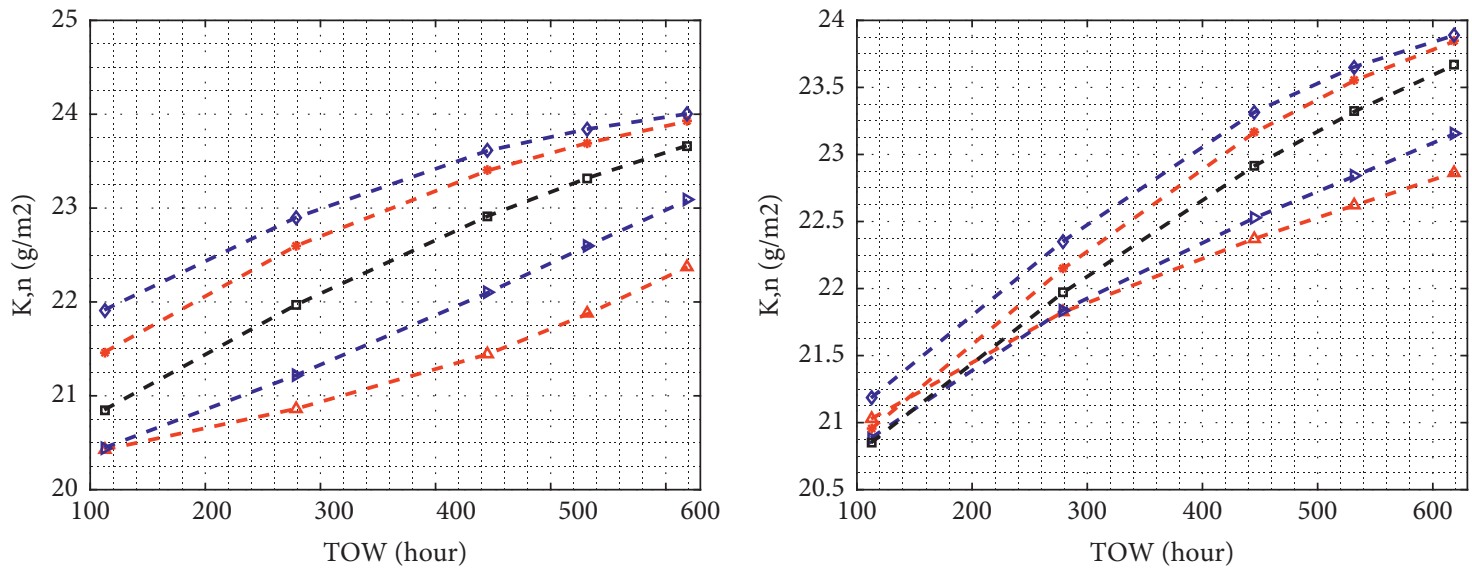

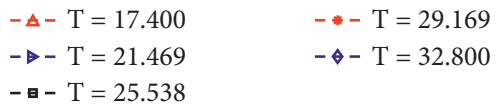

(a)

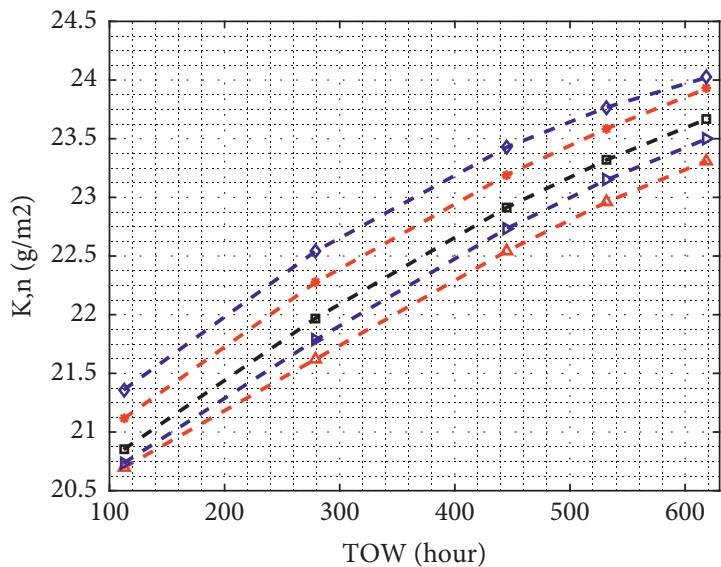

$-\Delta-C L-=5.641$

$\rightarrow-$ CL- $=9.263$

-

(c)

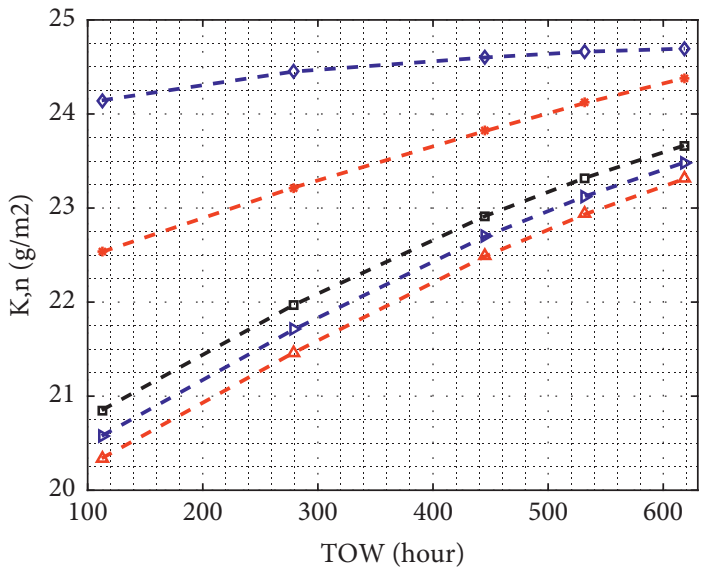

$-\Delta-\mathrm{Rf}=10.700$

- - Rf $=111.890$

一 $-\mathrm{Rf}=213.079$

$-\diamond-\mathrm{Rf}=1163.700$

- * CL- $=19.370$

$-\diamond-$ CL- $=25.854$

(e)

- $\Delta-\mathrm{RH}=65.000$

- $-\mathrm{RH}=73.521$

- - $\mathrm{RH}=82.042$

- $-\mathrm{RH}=86.521$

$-\diamond-\mathrm{RH}=91.000$

(b)

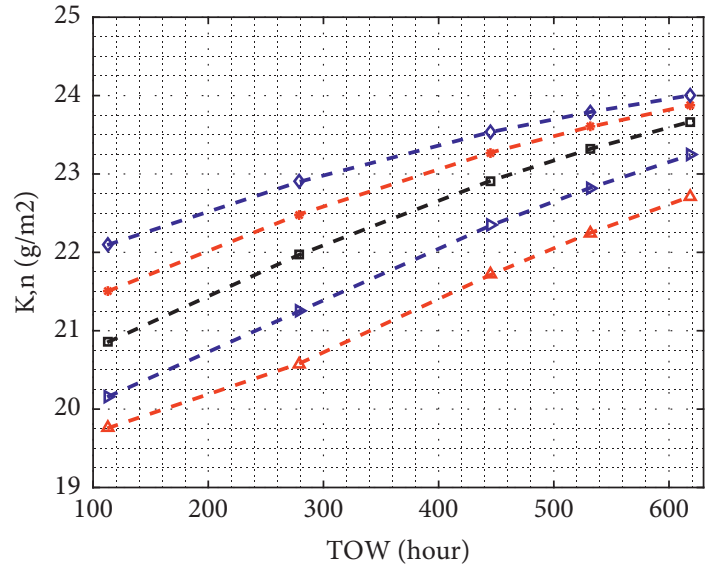

$-\Delta-\mathrm{SO} 2=5.141$

$\rightarrow-\mathrm{SO} 2=6.669$

- $-\mathrm{SO} 2=9.382$

- $-\mathrm{SO} 2=8.197$

(d)

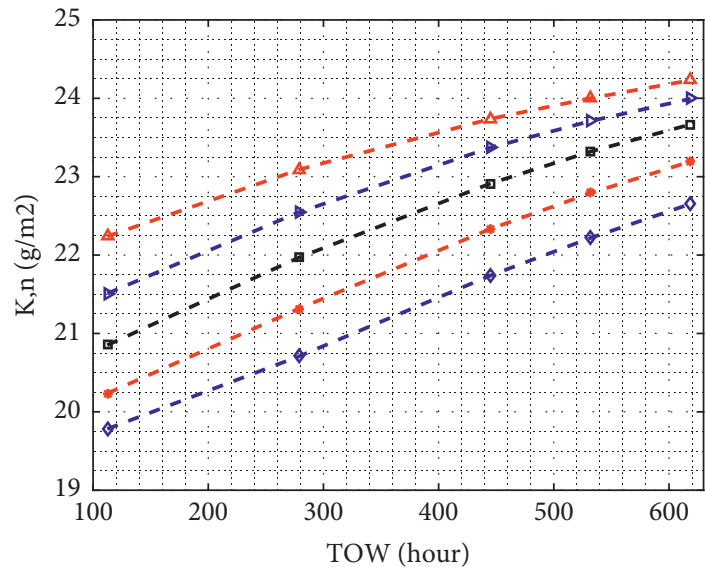

- $\Delta-\mathrm{HoS}=36.300$

- $*$ HoS $=208.521$

$-\gg-\mathrm{HoS}=91.271$

$-\diamond-\mathrm{HoS}=270.800$

Figure 15: Effects of the time of wetness (TOW). 

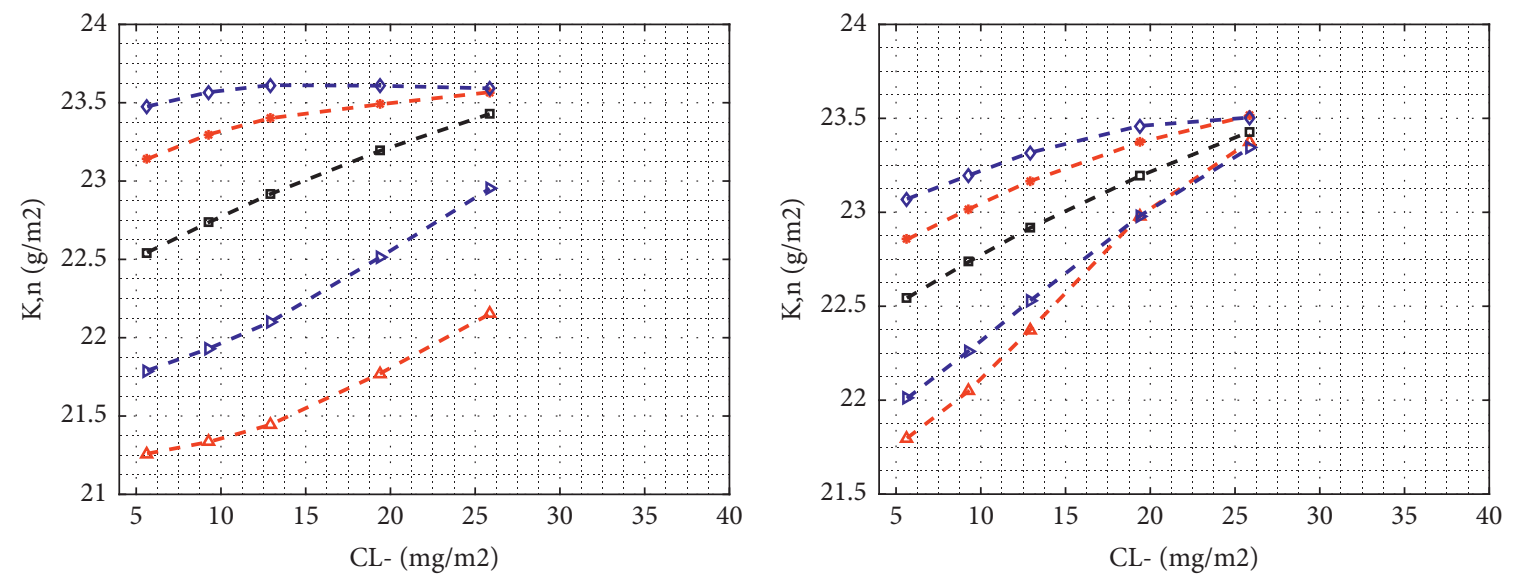

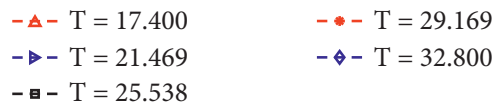

(a)

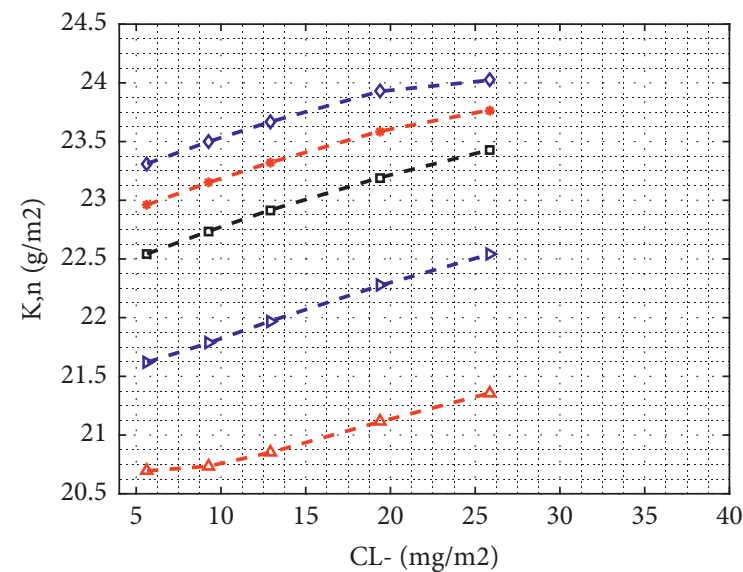

- $\Delta-$ TOW $=112.237$

- - TOW $=278.823$

-в - $\mathrm{TOW}=445.408$

(c)

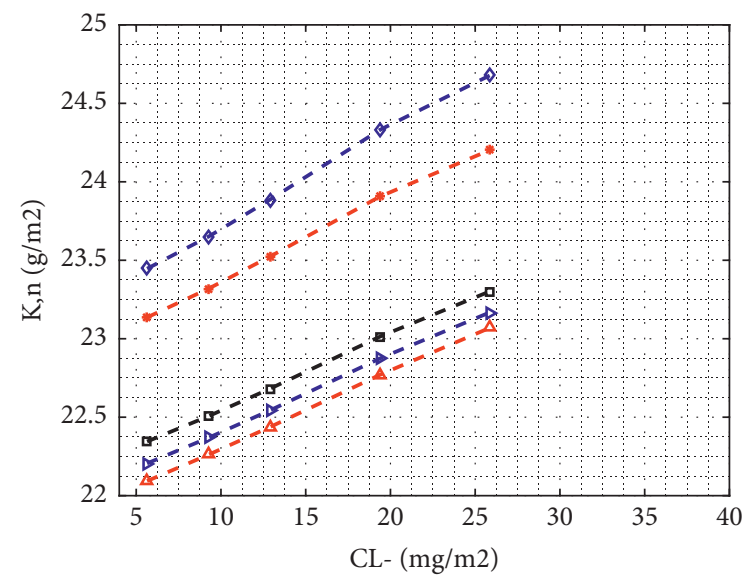

$$
\begin{array}{ll}
\text { - }-\mathrm{Rf}=10.700 & -\bullet-\mathrm{Rf}=688.390 \\
\text { - }-\mathrm{Rf}=111.890 & -\diamond-\mathrm{Rf}=1163.700 \\
\text {-в- Rf }=213.079 &
\end{array}
$$

(e)
$-*$ TOW $=532.109$

- - TOW $=618.809$

$$
\begin{array}{ll}
\text { - }-\mathrm{RH}=65.000 & -\bullet-\mathrm{RH}=86.521 \\
\text { 一- } \mathrm{RH}=73.521 & -\diamond-\mathrm{RH}=91.000 \\
\text { - }-\mathrm{RH}=82.042 &
\end{array}
$$

(b)

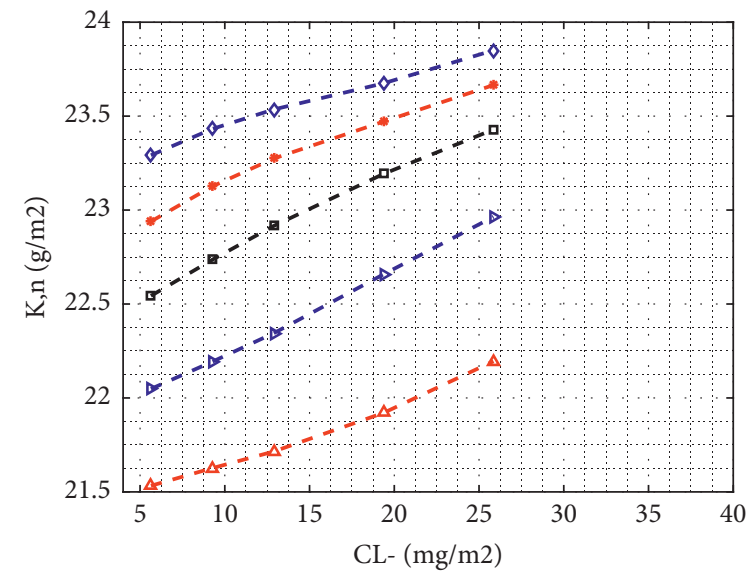

$$
\begin{array}{ll}
-\Delta-\mathrm{SO} 2=5.141 & -*-\mathrm{SO} 2=9.382 \\
\text { - - SO2 }=6.669 & -\diamond-\mathrm{SO} 2=10.566 \\
\text { - }-\mathrm{SO} 2=8.197 &
\end{array}
$$

(d)

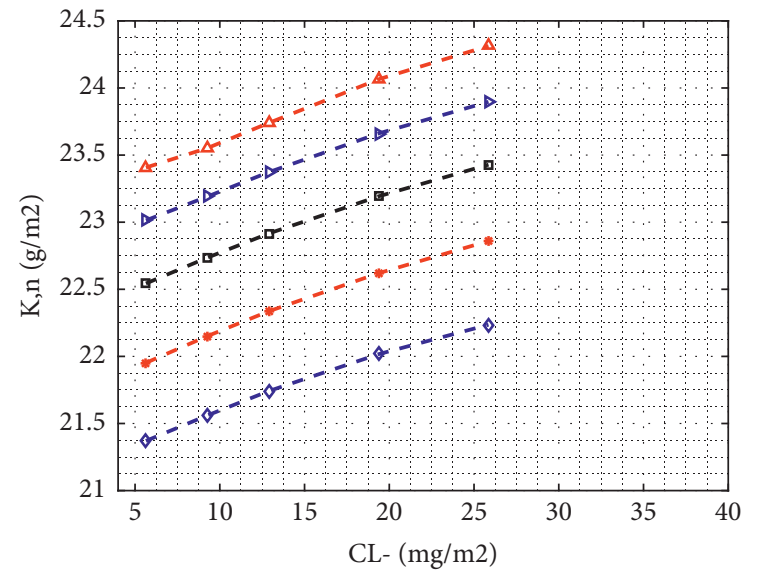

$$
\begin{array}{ll}
-\Delta-\mathrm{HoS}=36.300 & -\bullet-\mathrm{HoS}=208.521 \\
\text { - }-\mathrm{HoS}=91.271 & -\diamond-\mathrm{HoS}=270.800 \\
\text { - }-\mathrm{HoS}=146.242 &
\end{array}
$$

(f)

FIgURE 16: Effect of the average chloride deposition rate. 

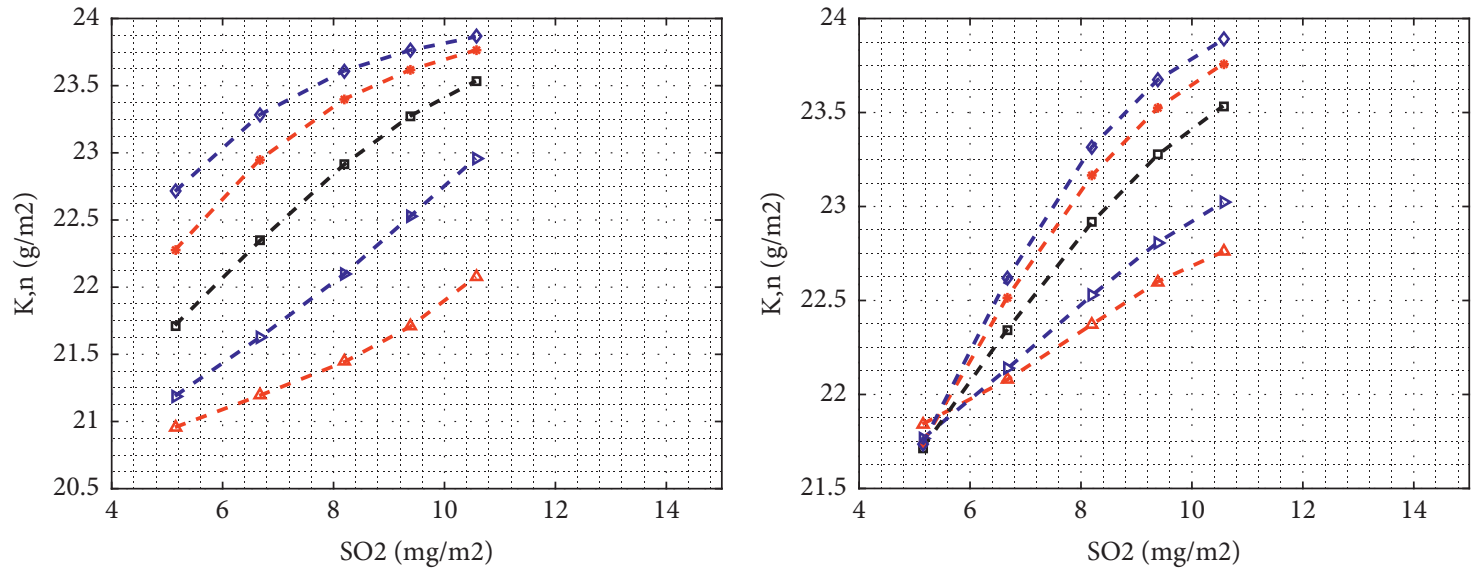

$\begin{aligned} \text { - } \Delta-\mathrm{T} & =17.400 \\ \text { - - } \mathrm{T} & =21.469 \\ \text {-в- } \mathrm{T} & =25.538\end{aligned}$

- $-\mathrm{T}=29.169$

$-\diamond-\mathrm{T}=32.800$

(a)

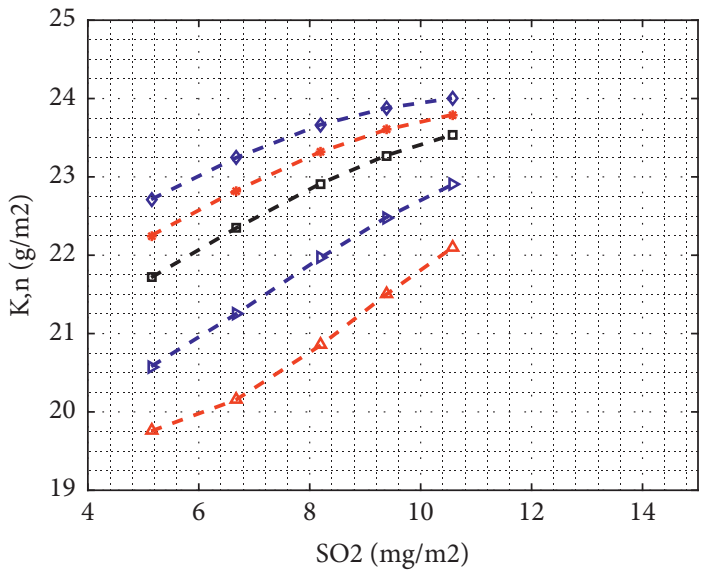

- $\Delta-$ TOW $=112.237 \quad-\cdots$ - TOW $=532.109$

$\rightarrow-$ TOW $=278.823$

$-\diamond-$ TOW $=618.809$

- - TOW $=445.408$

(c)

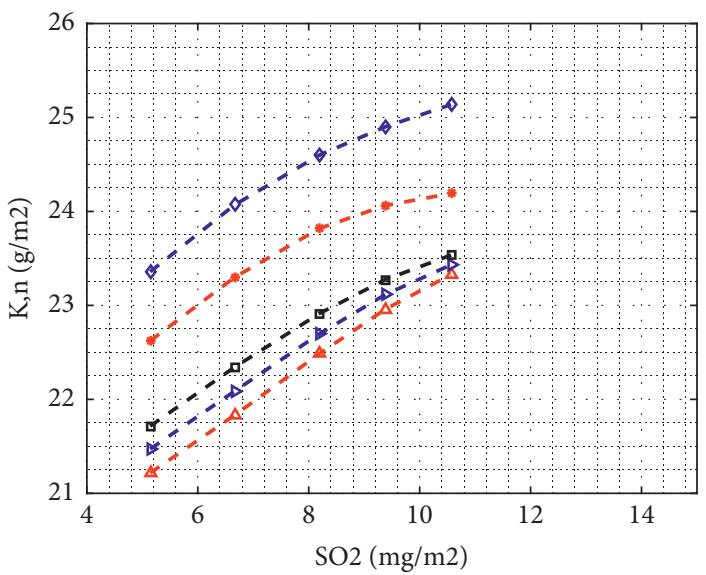

- A- Rf $=10.700$

- $-\mathrm{Rf}=111.890$

- $-\mathrm{Rf}=213.079$
- $\mathrm{A}-\mathrm{RH}=65.000 \quad-*-\mathrm{RH}=86.521$

$\rightarrow-\mathrm{RH}=73.521$

$-\diamond-\mathrm{RH}=91.000$

(b)

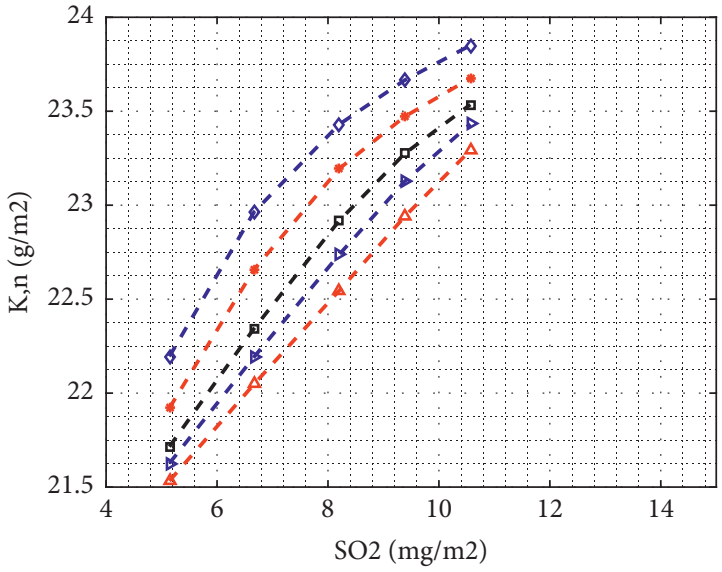

$$
\begin{aligned}
& \text { - } \Delta-\mathrm{CL}-=5.641 \quad-*-\mathrm{CL}-=19.370 \\
& \rightarrow-\text { CL- }=9.263 \\
& -\diamond-\text { CL- }=25.854
\end{aligned}
$$$$
\text { - }-\mathrm{CL}-\mathrm{C}=12.886
$$

(d)

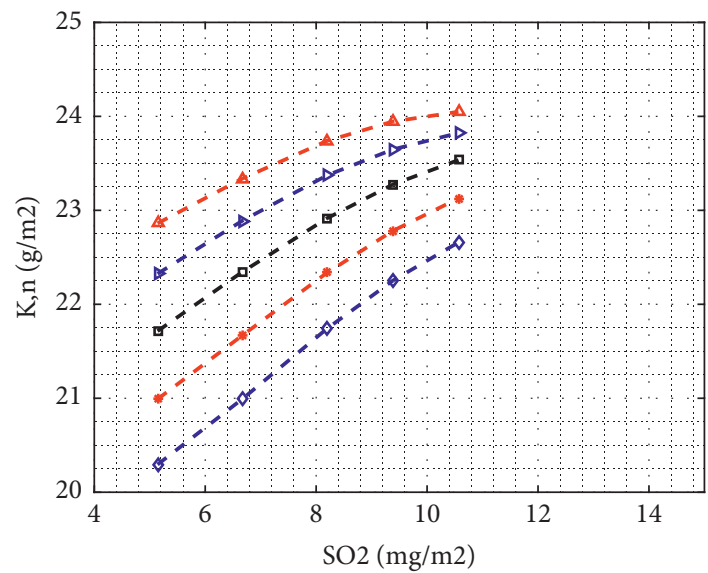

$\begin{array}{rlrl}-\star-H o S & =36.300 & ---\mathrm{HoS}=208.521 \\ -\triangleright-\mathrm{HoS}=91.271 & -\diamond-\mathrm{HoS}=270.800\end{array}$

- $\boldsymbol{\text { в }}$ HoS $=146.242$

(f)

(e)

FIGURE 17: Effect of the average sulfur dioxide deposition rate. 

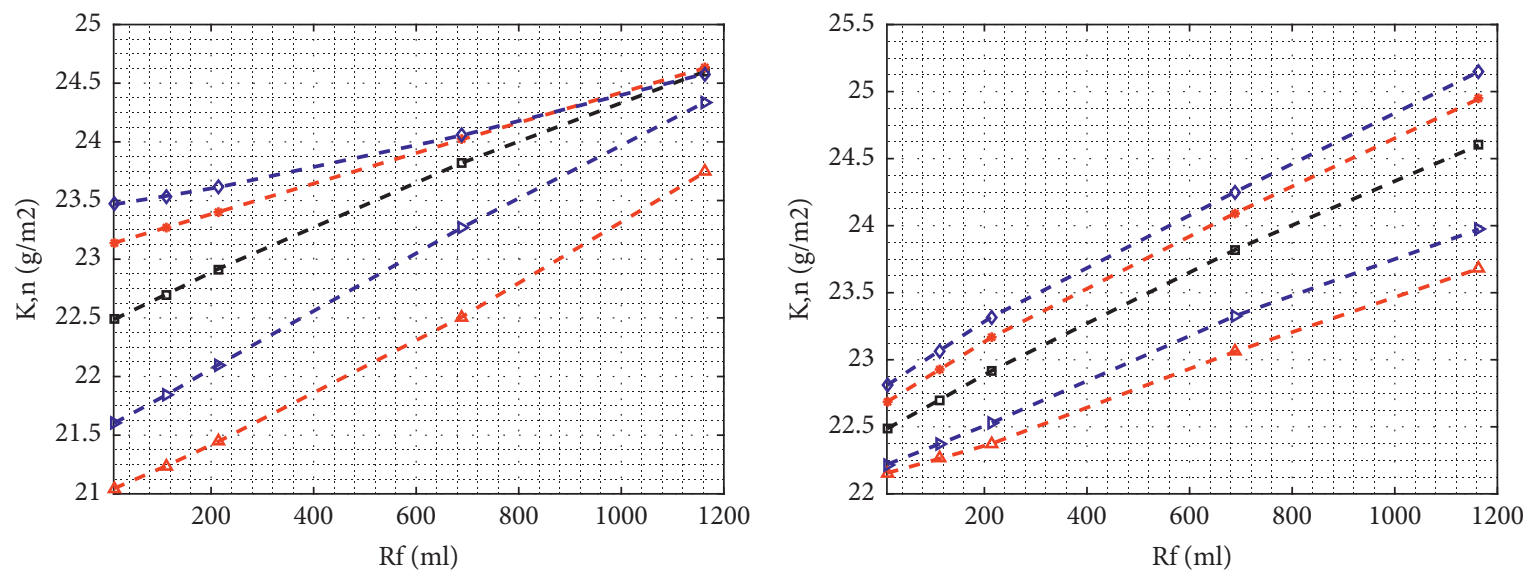

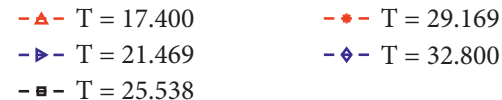

(a)

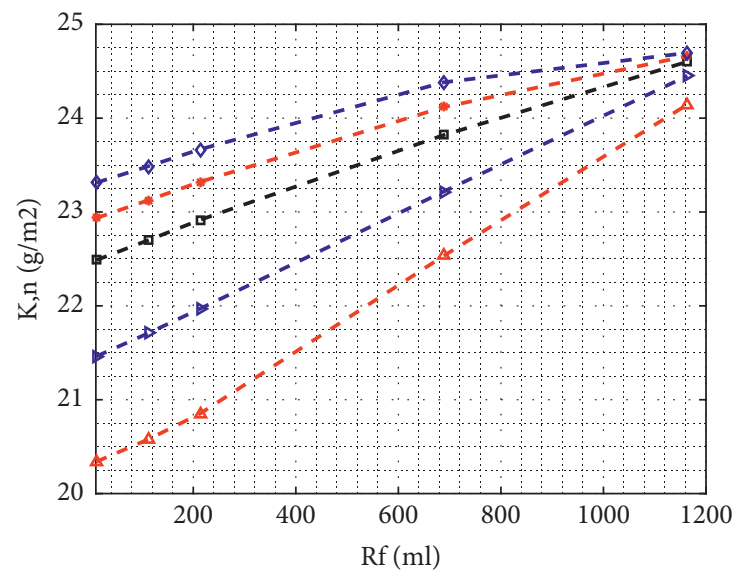

$-\triangle-$ TOW $=112.237$

$\rightarrow-$ TOW $=278.823$

$-\because-\mathrm{TOW}=445.408$

(c)

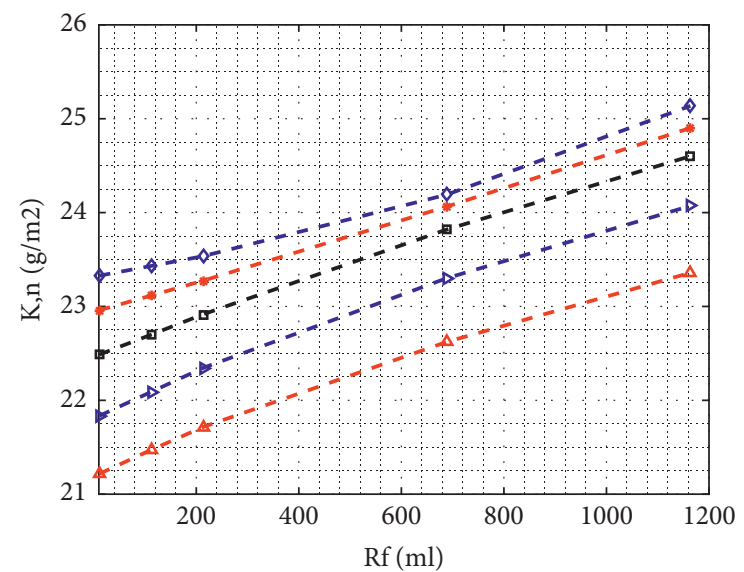

$-\Delta-\mathrm{SO} 2=5.141$

$\rightarrow-\mathrm{SO} 2=6.669$

- - $\mathrm{SO} 2=8.197$

- - $\mathrm{SO} 2=9.382$

$-\diamond-\mathrm{SO} 2=10.566$
$-*$ TOW $=532.109$

$-\diamond-$ TOW $=618.809$

(e)

$$
\begin{array}{ll}
\text { - }-\mathrm{RH}=65.000 & -\bullet-\mathrm{RH}=86.521 \\
\text { - }-\mathrm{RH}=73.521 & -\diamond-\mathrm{RH}=91.000 \\
\text { - } \text { - } \mathrm{RH}=82.042 &
\end{array}
$$

(b)

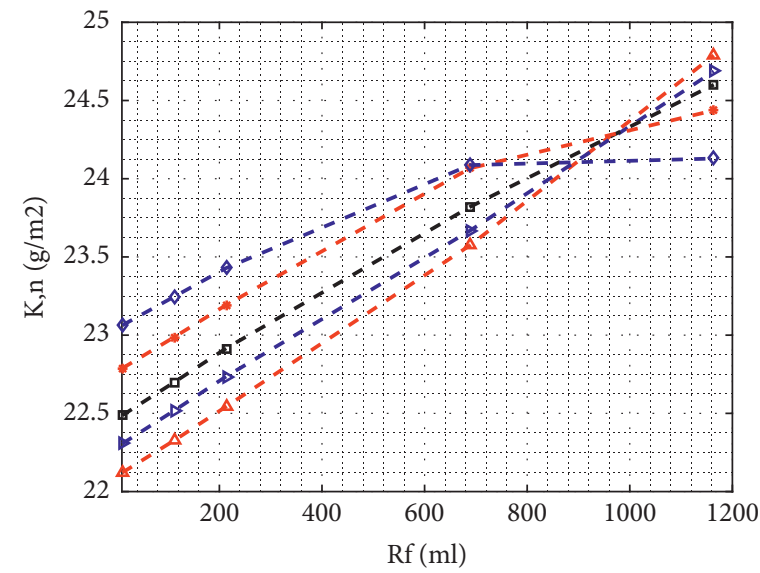

$$
\begin{array}{rlrl}
-\Delta-C L- & =5.641 & & - \text { CL- }=19.370 \\
\text { - - CL- }=9.263 & & -\diamond-\text { CL- }=25.854 \\
\text {-в- CL- }=12.886 &
\end{array}
$$

(d)

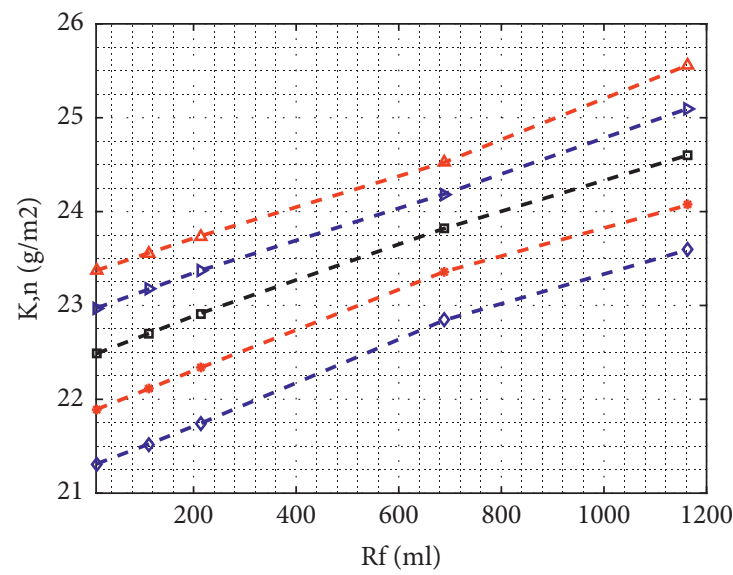

$$
\begin{array}{ll}
-\Delta-\mathrm{HoS}=36.300 & --\mathrm{HoS}=208.521 \\
-\triangleright-\mathrm{HoS}=91.271 & -\diamond-\mathrm{HoS}=270.800
\end{array}
$$$$
\text { - }-\mathrm{HoS}=146.242
$$

(f)

Figure 18: Effects of the rainfall. 

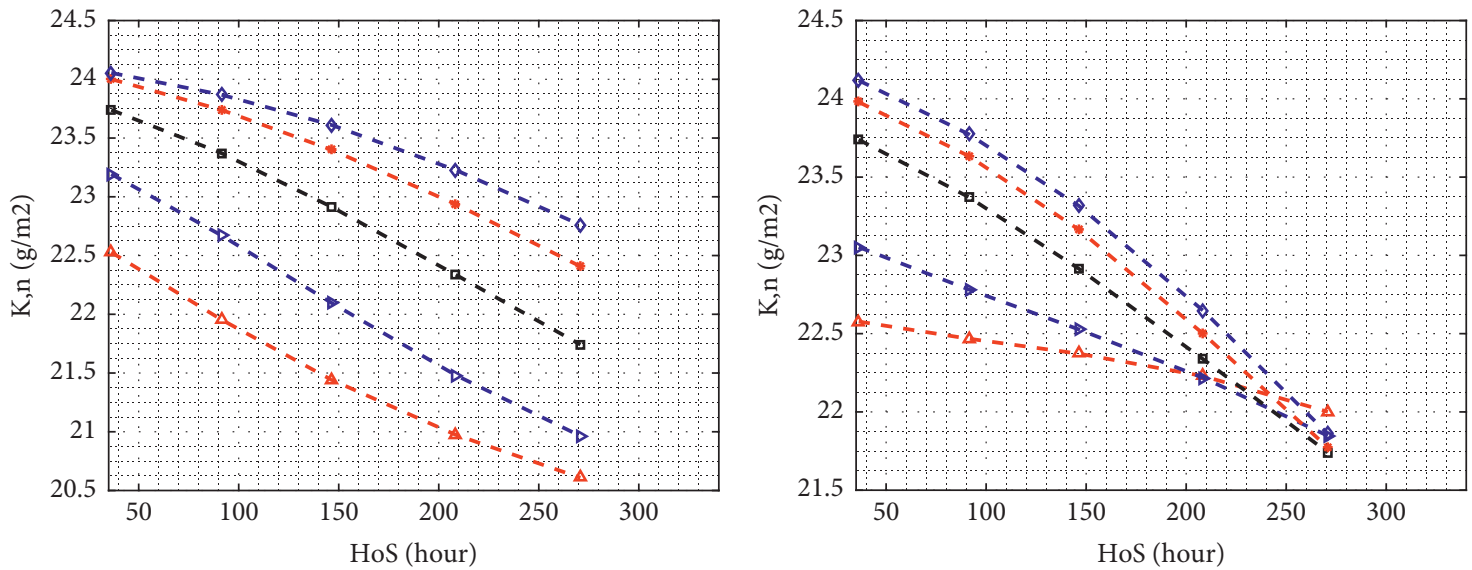

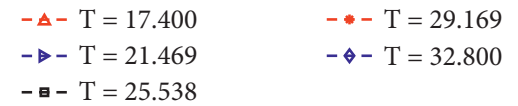

(a)

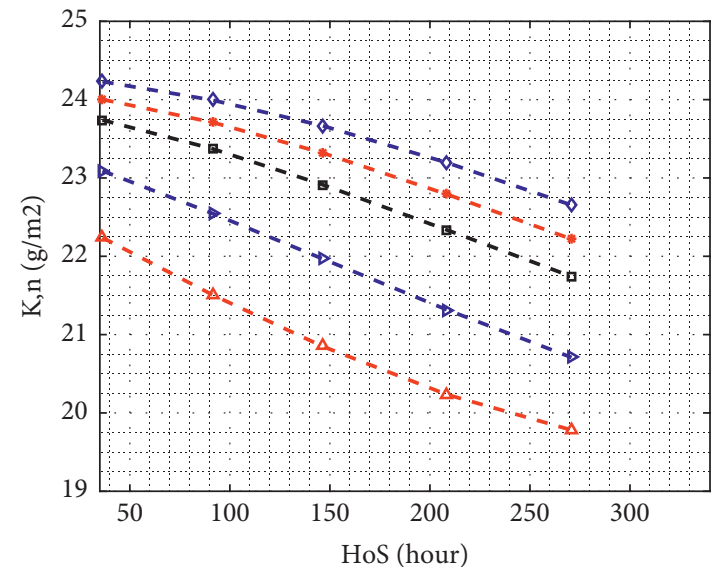

$$
\begin{aligned}
& -\triangle-\text { TOW }=112.237 \quad-- \text { TOW }=532.109 \\
& -\triangleright-\text { TOW }=278.823 \quad-\diamond-\text { TOW }=618.809 \\
& -\because-\mathrm{TOW}=445.408
\end{aligned}
$$

(c)

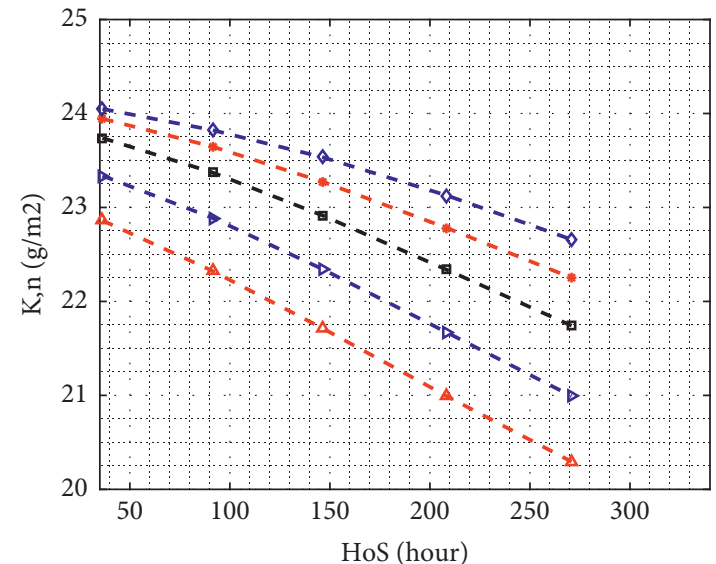

$$
\begin{array}{ll}
-\Delta-\mathrm{SO} 2=5.141 & -\bullet \mathrm{SO} 2=9.382 \\
-\triangleright-\mathrm{SO} 2=6.669 & -\diamond-\mathrm{SO} 2=10.566 \\
-\bullet-\mathrm{SO} 2=8.197 &
\end{array}
$$

(e)

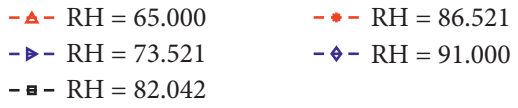

(b)

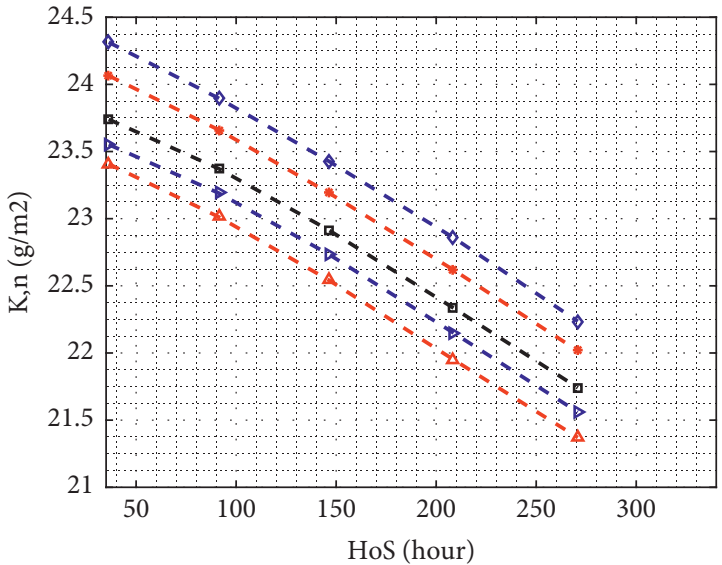

$$
\begin{array}{ll}
-\Delta-C L-=5.641 & -\bullet-C L-=19.370 \\
-\diamond-C L-=9.263 & -\diamond-C L-=25.854
\end{array}
$$

(d)

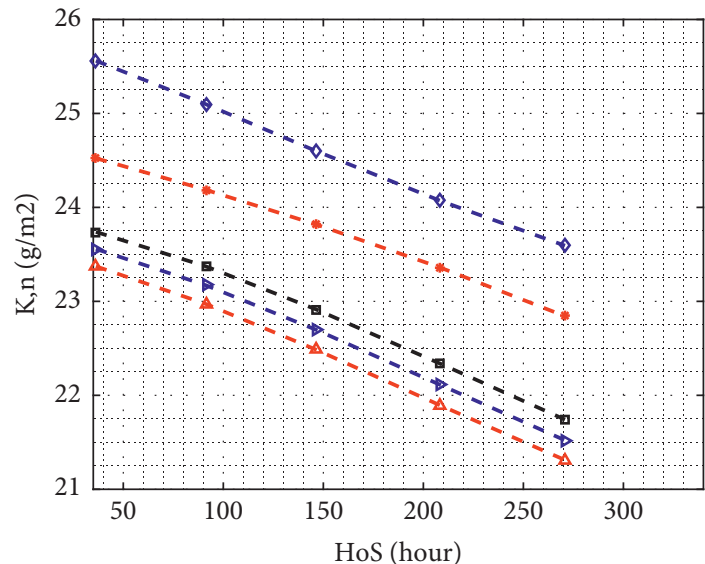

$$
\begin{array}{ll}
-\Delta-\mathrm{Rf}=10.700 & -\bullet \mathrm{Rf}=688.390 \\
-\diamond-\mathrm{Rf}=111.890 & -\diamond-\mathrm{Rf}=1163.700 \\
\text { - }-\mathrm{Rf}=213.079 &
\end{array}
$$

(f)

Figure 19: Effects of the hours of sunshine. 


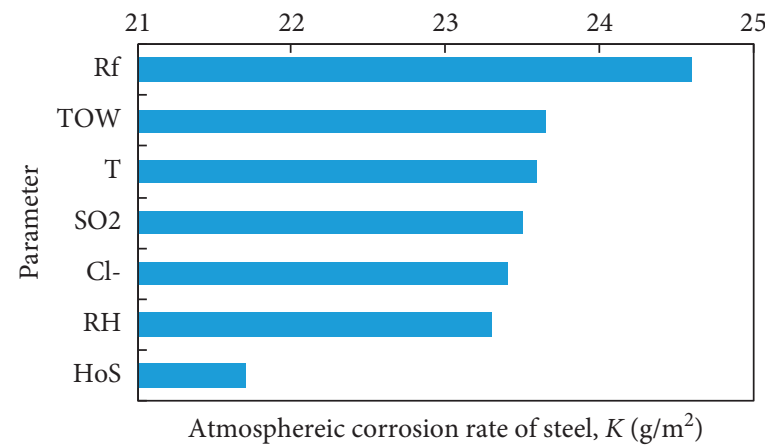

Figure 20: Sensitivity of input parameters to $K$.

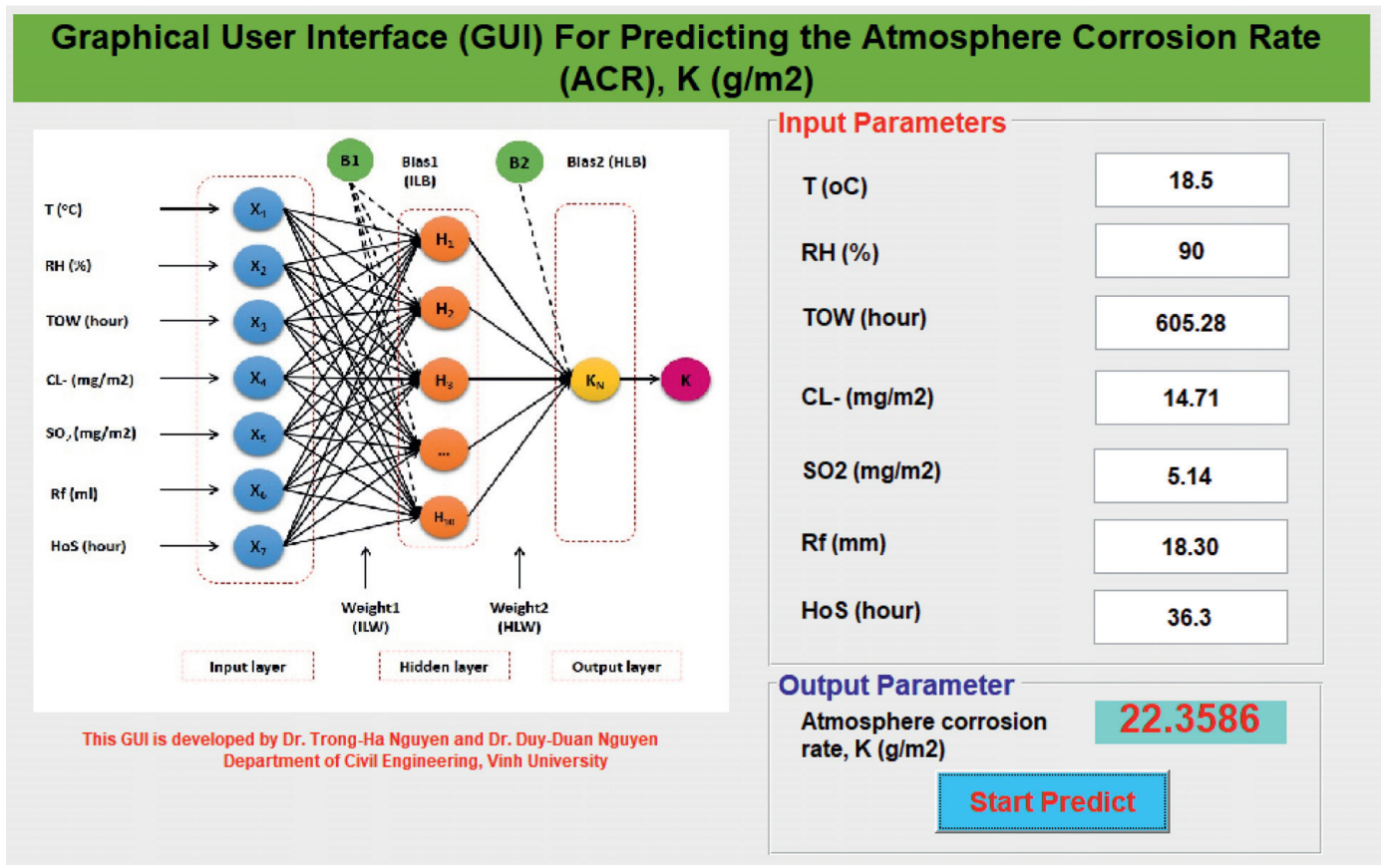

Figure 21: Practical GUI tool for predicting $K$.

TABLe 7: Coefficients for formulation of the atmospheric corrosion rate.

\begin{tabular}{|c|c|c|c|c|c|c|c|c|c|}
\hline$i$ & $h_{i}$ & $c_{i o}$ & $c_{i 1}$ & $c_{i 2}$ & $c_{i 3}$ & $c_{i 4}$ & $c_{i 5}$ & $c_{i 6}$ & $c_{i 7}$ \\
\hline 0 & 0.0493 & & & & & & & & \\
\hline 1 & 0.0894 & 2.0629 & -1.0393 & 0.9389 & 0.1480 & 0.6153 & 0.8763 & 0.4277 & 0.6584 \\
\hline 2 & -0.1287 & 1.5126 & -0.1523 & 1.2986 & 0.8260 & 0.9740 & -0.4331 & -0.2793 & 0.6598 \\
\hline 3 & -0.0497 & -0.9743 & 0.4505 & 0.5804 & -0.2783 & 0.1327 & 0.2816 & 0.1549 & -1.7495 \\
\hline 4 & 0.9864 & -0.0732 & -0.0674 & -1.0076 & 1.3142 & 0.1547 & 0.0209 & 0.6745 & 0.3935 \\
\hline 5 & -0.3221 & -0.0563 & 0.2031 & 0.3162 & 1.0973 & -0.9569 & -1.0679 & 0.5407 & 0.5098 \\
\hline 6 & -0.2042 & -0.0721 & 1.0733 & -0.8696 & 0.9764 & 1.1741 & -0.3816 & -0.2964 & -0.2766 \\
\hline 7 & 0.5900 & 0.7026 & 0.6368 & -0.3613 & -0.4065 & -0.1896 & -0.7083 & 0.6785 & -0.7133 \\
\hline 8 & 0.0918 & 1.5238 & 0.9555 & 0.3775 & -0.2519 & -0.9748 & 0.8895 & -0.4711 & 1.0209 \\
\hline 9 & 0.1518 & -1.2355 & -0.5890 & 0.7354 & -1.1184 & 1.0177 & -0.2707 & 0.3039 & -0.5342 \\
\hline 10 & 0.1086 & 2.3844 & 0.3684 & 0.7974 & 0.7287 & 0.8352 & 0.7734 & 0.3575 & -0.5042 \\
\hline
\end{tabular}




\section{Conclusions}

A practical ANN model was developed to predict the atmospheric corrosion rate of carbon steel based on a set of 240 experimental data samples. The results of the proposed model were compared with those of three regression models and three existing formulas. Additionally, a series of parametric studies were performed to evaluate the effects of input parameters on the atmospheric corrosion rate. The following conclusions are drawn:

The developed ANN model in this study predicted the atmospheric corrosion rate of carbon steel more accurately than the regression models and existing equations. The accuracy of the model was verified by the statistical properties including RMSE, MAPE, $R^{2}$, and $r$ value.

The rainfall and hours of sunshine were the most influential parameters on predicting the atmospheric corrosion rate. Meanwhile, the average chloride ion, the average temperature, and the time of wetness were less sensitive to the atmospheric corrosion rate.

An ANN model-based formula, which considered all seven input parameters, was proposed to calculate the atmospheric corrosion rate of carbon steel.

A graphical user interface tool was developed and easily applied for simplifying the prediction of the atmospheric corrosion rate of carbon steel.

\section{Data Availability}

All the data supporting the key findings of this paper are presented in the figures and tables of the article. Requests for other data will be considered by the corresponding author.

\section{Conflicts of Interest}

The authors declare that they have no conflicts of interest.

\section{Acknowledgments}

This study was supported by the Ministry of Education and Training of Vietnam (Grant no. B2020-TDV-05).

\section{References}

[1] A. N. Kallias, B. Imam, and M. K. Chryssanthopoulos, "Performance profiles of metallic bridges subject to coating degradation and atmospheric corrosion," Structure and Infrastructure Engineering, vol. 13, no. 4, pp. 440-453, 2017.

[2] M. Morcillo, B. Chico, I. Díaz, H. Cano, and D. De la Fuente, "Atmospheric corrosion data of weathering steels. A review," Corrosion Science, vol. 77, pp. 6-24, 2013.

[3] S. Sabir and A. A. Ibrahim, "Influence of atmospheric pollution on corrosion of materials in Saudi Arabia," Corrosion Engineering, Science and Technology, vol. 52, no. 4, pp. 276-282, 2017.

[4] Z. Cui, X. Li, H. Zhang et al., "Atmospheric corrosion behavior of 2A12 aluminum alloy in a tropical marine environment," Advances in Materials Science and Engineering, vol. 2015, Article ID 163205, 17 pages, 2015.
[5] M. Esmaily, M. Shahabi-Navid, J.-E. Svensson, M. Halvarsson, L. Nyborg, and Y. Cao, "Influence of temperature on the atmospheric corrosion of the $\mathrm{Mg}-\mathrm{Al}$ alloy AM50," Corrosion Science, vol. 90, pp. 420-433, 2015.

[6] N. LeBozec, M. Jonsson, and D. Thierry, "Atmospheric corrosion of magnesium alloys: influence of temperature, relative humidity, and chloride deposition," Corrosion, vol. 60, no. 4, pp. 356-361, 2004.

[7] F. Samie, J. Tidblad, V. Kucera, and C. Leygraf, "Atmospheric corrosion effects of HNO3-influence of temperature and relative humidity on laboratory-exposed copper," Atmospheric Environment, vol. 41, no. 7, pp. 1374-1382, 2007.

[8] X. Wang, X. Li, and X. Tian, "Influence of temperature and relative humidity on the atmospheric corrosion of zinc in field exposures and laboratory environments by atmospheric corrosion monitor," International Journal Electrochem Sci, vol. 10, no. 10, pp. 8361-8373, 2015.

[9] I. S. Cole, T. Muster, N. Azmat, M. Venkatraman, and A. Cook, "Multiscale modelling of the corrosion of metals under atmospheric corrosion," Electrochimica Acta, vol. 56, no. 4, pp. 1856-1865, 2011.

[10] D. Kong, C. Dong, Y. Fang et al., "Long-term corrosion of copper in hot and dry atmosphere in Turpan, China," Journal of Materials Engineering and Performance, vol. 25, no. 7, pp. 2977-2984, 2016.

[11] F. Corvo, J. Minotas, J. Delgado, and C. Arroyave, "Changes in atmospheric corrosion rate caused by chloride ions depending on rain regime," Corrosion Science, vol. 47, no. 4, pp. 883-892, 2005.

[12] L. Veleva, M. Acosta, and E. Meraz, "Atmospheric corrosion of zinc induced by runoff," Corrosion Science, vol. 51, no. 9, pp. 2055-2062, 2009.

[13] C. Arroyave, F. Lopez, and M. Morcillo, "The early atmospheric corrosion stages of carbon steel in acidic fogs," Corrosion Science, vol. 37, no. 11, pp. 1751-1761, 1995.

[14] S. Feliu and M. Morcillo, "The prediction of atmospheric corrosion from meteorological and pollution parameters-I," Annual corrosion. Corrosion Science, vol. 34, no. 3, pp. 403414, 1993.

[15] Y. C. Sica, E. D. Kenny, K. F. Portella, and D. F. Campos Filho, "Atmospheric corrosion performance of carbon steel, galvanized steel, aluminum and copper in the North Brazilian coast," Journal of the Brazilian Chemical Society, vol. 18, no. 1, pp. 153-166, 2007.

[16] R. Vera, F. Guerrero, D. Delgado, and R. Araya, "Atmospheric corrosion of galvanized steel and precipitation runoff from zinc in a marine environment," Journal of the Brazilian Chemical Society, vol. 24, no. 3, pp. 449-458, 2013.

[17] J. Tidblad, "Atmospheric corrosion of metals in 2010-2039 and 2070-2099," Atmospheric Environment, vol. 55, pp. 1-6, 2012.

[18] M. Morcillo, "Atmospheric corrosion in Ibero-America: the MICAT project," in Atmospheric CorrosionASTM International, West Conshohocken, PA, USA, 1995.

[19] D. Knotkova, V. Kucera, S. W. Dean, and P. Boschek, "Classification of the corrosivity of the atmosphere," Standardized Classification System and Approach for Adjustment, Outdoor atmospheric corrosion ASTM International, West Conshohocken, PA, USA, 2002.

[20] Y. M. Panchenko and A. I. Marshakov, "Prediction of firstyear corrosion losses of carbon steel and zinc in continental regions," Materials, vol. 10, no. 4, p. 422, 2017.

[21] P. Roberge, R. Klassen, and P. Haberecht, "Atmospheric corrosivity modeling - a review," Materials \& Design, vol. 23, no. 3, pp. 321-330, 2002. 
[22] J. Tidblad, V. Kucera, A. A. Mikhailov et al., UN ECE ICP Materials: Dose-Response Functions on Dry and Wet Acid Deposition Effects after 8 Years of Exposure, Springer, no. 2001, New York, NY, USA, 2000.

[23] V. Kucera, J. Tidblad, K. Kreislova et al., "UN/ECE ICP materials dose-response functions for the multi-pollutant situation," Acid Rain-Deposition to Recovery, Springer, New York, NY, USA, 2007.

[24] A. Mikhailov, J. Tidblad, and V. Kucera, "The classification system of ISO 9223 standard and the dose-response functions assessing the corrosivity of outdoor atmospheres," Protection of Metals, vol. 40, no. 6, pp. 541-550, 2004.

[25] B. Chico, D. De la Fuente, I. Díaz, J. Simancas, and M. Morcillo, "Annual atmospheric corrosion of carbon steel worldwide. An integration of ISOCORRAG, ICP/UNECE and MICAT databases," Materials, vol. 10, no. 6, p. 601, 2017.

[26] M. E. A. B. Seghier, B. Keshtegar, K. F. Tee, T. Zayed, R. Abbassi, and N. T. Trung, "Prediction of maximum pitting corrosion depth in oil and gas pipelines," Engineering Failure Analysis, vol. 112, Article ID 104505, 2020.

[27] M. E. A. B. Seghier, B. Keshtegar, M. Taleb-Berrouane, R. Abbassi, and N.-T. Trung, "Advanced intelligence frameworks for predicting maximum pitting corrosion depth in oil and gas pipelines," Process Safety and Environmental Protection, vol. 147, pp. 818-833, 2021.

[28] M. E. A. B. Seghier, J. A. Corriea, J. Jafari-Asl, A. Malekjafarian, V. Plevris, and N.-T. Trung, "On the modeling of the annual corrosion rate in main cables of suspension bridges using combined soft computing model and a novel nature-inspired algorithm," Neural Computing \& Applications, pp. 1-17, 2021.

[29] Y. Diao, L. Yan, and K. Gao, "Improvement of the machine learning-based corrosion rate prediction model through the optimization of input features," Materials \& Design, vol. 198, Article ID 109326, 2021.

[30] V. Díaz and C. López, "Discovering key meteorological variables in atmospheric corrosion through an artificial neural network model," Corrosion Science, vol. 49, no. 3, pp. 949$962,2007$.

[31] J. Long, X. Li, Y. Zhong, and D. Peng, "Application of bp neural networks on the thickness prediction of sherardizing coating," Transactions of the Indian Institute of Metals, vol. 72, no. 9, pp. 2443-2448, 2019.

[32] S. K. Tripathy, I. Mohanty, and L. O. Filippov, “Application of artificial neural networks to predict dry magnetic separation of low-grade hematite fines," Transactions of the Indian Institute of Metals, vol. 73, pp. 1797-1807, 2020.

[33] E. D. Kenny, R. S. Paredes, L. A. de Lacerda, Y. C. Sica, G. P. de Souza, and J. Lázaris, "Artificial neural network corrosion modeling for metals in an equatorial climate," Corrosion Science, vol. 51, no. 10, pp. 2266-2278, 2009.

[34] R. Vera, R. Araya, M. Bagnara, A. Díaz-Gómez, and S. Ossandón, "Atmospheric corrosion of copper exposed to different environments in the region of Valparaiso, Chile," Materials and Corrosion, vol. 68, no. 3, pp. 316-328, 2017.

[35] S. Pintos, N. V. Queipo, O. T. de Rincón, A. Rincón, and M. Morcillo, "Artificial neural network modeling of atmospheric corrosion in the MICAT project," Corrosion Science, vol. 42 , no. 1 , pp. $35-52,2000$.

[36] L. C. Rowe, "Effect of sunlight on the corrosion of steel," Corrosion, vol. 17, no. 6, pp. 267t-8t, 1961.

[37] T.-H. Nguyen, The study and propose solutions reliability and durability of steel structures in the more sulfur dioxides and chlorides environment using risk analysis, Ministry of Education and Training of Vietnam, Hanoi, Vietnam, 2020.

[38] En-ISO:9226, Corrosion of Metals and Alloys - Corrosivity of Atmospheres - Method of Determination of Corrosivity Using the Corrosion Loss Standard Specimens, International Organization for Standardization (ISO), Geneva, Switzerland, 2012.

[39] S. C. Chapra and R. P. Canale, Numerical Methods for Engineers, McGraw-Hill Higher Education, Boston, MA, USA, 2010.

[40] N. Vu-Bac, T. Lahmer, Y. Zhang, X. Zhuang, and T. Rabczuk, "Stochastic predictions of interfacial characteristic of polymeric nanocomposites (PNCs)," Composites Part B: Engineering, vol. 59, pp. 80-95, 2014.

[41] W. B. Chaabene, M. Flah, and M. L. Nehdi, "Machine learning prediction of mechanical properties of concrete: critical review," Construction and Building Materials, vol. 260, Article ID 119889, 2020.

[42] O. I. Abiodun, A. Jantan, A. E. Omolara, K. V. Dada, N. A. Mohamed, and H. Arshad, "State-of-the-art in artificial neural network applications: a survey," Heliyon, vol. 4, no. 11, Article ID e00938, 2018.

[43] D.-D. Nguyen, V.-L. Tran, D.-H. Ha, V.-Q. Nguyen, and T.-H. Lee, "A machine learning-based formulation for predicting shear capacity of squat flanged RC walls," Structure, vol. 29, pp. 1734-1747, 2021.

[44] I. Goodfellow, Y. Bengio, and A. Courville, Deep Learning (Adaptive Computation and Machine Learning Series), MIT Press, Cambridge, MA, USA, 2017.

[45] H. Allahyari, I. M. Nikbin, S. Rahimi, and A. Heidarpour, "A new approach to determine strength of Perfobond rib shear connector in steel-concrete composite structures by employing neural network," Engineering Structures, vol. 157, pp. 235-249, 2018.

[46] V.-L. Tran, D.-K. Thai, and S.-E. Kim, "Application of ANN in predicting ACC of SCFST column," Composite Structures, vol. 228, Article ID 111332, 2019.

[47] V.-L. Tran, D.-K. Thai, and D.-D. Nguyen, "Practical artificial neural network tool for predicting the axial compression capacity of circular concrete-filled steel tube columns with ultra-high-strength concrete," Thin-Walled Structures, vol. 151, Article ID 106720, 2020.

[48] E. M. Golafshani and A. Ashour, "A feasibility study of BBP for predicting shear capacity of FRP reinforced concrete beams without stirrups," Advances in Engineering Software, vol. 97, pp. 29-39, 2016.

[49] T.-H. Nguyen, N.-L. Tran, and D.-D Nguyen, “.. Prediction of critical buckling load of web tapered I-section steel columns using artificial neural networks," International Journal of Steel Structures, vol. 21, no. 4, pp. 1159-1181, 2021.

[50] M. N. Hadi, "Neural networks applications in concrete structures," Computers \& Structures, vol. 81, no. 6, pp. 373-381, 2003.

[51] A. Ranganathan, "The levenberg-marquardt algorithm," Tutoral on LM algorithm, vol. 11, no. 1, pp. 101-110, 2004.

[52] V.-L. Tran and S.-E. Kim, "Efficiency of three advanced datadriven models for predicting axial compression capacity of CFDST columns," Thin-Walled Structures, vol. 152, Article ID 106744, 2020.

[53] V.-L. Tran, D.-K. Thai, and S.-E. Kim, "A new empirical formula for prediction of the axial compression capacity of CCFT columns," Steel and Composite Structures, vol. 33, no. 2, pp. 181-194, 2019. 
[54] V.-L. Tran and S.-E. Kim, "A practical ANN model for predicting the PSS of two-way reinforced concrete slabs," Engineering with Computers, pp. 1-25, 2020.

[55] M.-S. T. Nguyen, D.-K. Thai, and S.-E. Kim, "Predicting the axial compressive capacity of circular concrete filled steel tube columns using an artificial neural network," Steel and Composite Structures, vol. 35, no. 3, pp. 415-437, 2020.

[56] I. Mathworks, MATLAB and Statistics Toolbox Release 2018b, Natick, MA, United States, 2018.

[57] J. Tidblad, A. A. Mikhailov, and V. Kucera, "Application of a model for prediction of atmospheric corrosion in tropical environments," Marine Corrosion in Tropical Environments, ASTM International, West Conshohocken, PA, USA, 2000.

[58] Y. Cui, Y. Qin, D. Dilimulati, and Y. Wang, "The effect of chlorine ion on metal corrosion behavior under the scratch defect of coating," International Journal of Corrosion, vol. 2019, Article ID 7982893, 11 pages, 2019.

[59] D. G. Gillette, "Sulfur dioxide and material damage," Journal of the Air Pollution Control Association, vol. 25, no. 12, pp. 1238-1243, 1975.

[60] M. Nguyen, X. Wang, and R. Leicester, "An assessment of climate change effects on atmospheric corrosion rates of steel structures," Corrosion Engineering, Science and Technology, vol. 48, no. 5, pp. 359-369, 2013. 